\title{
Luis de Galinsoga i els seus amics: cinc anys commemorant la liberación de Barcelona, 1940-1944
}

\author{
FRANCESC ViLANOVA \\ Fundació Carles Pi i Sunyer \\ Centre d’Estudis sobre les Ėpoques Franquista i Democràtica (UAB)
}

Resum: En el moment que Luis Martínez de Galinsoga va assumir la direcció del diari barceloní La Vanguardia — des del final de gener de 1939, La Vanguardia Española-, va iniciar un procés de transformació del diari, seguint les directrius oficials, que es va fer ràpidament visible en dos àmbits: la conversió del mitjà en un dels portaveus més ortodoxos de les celebracions del nou calendari franquista i l'intent de fomentar un nucli "intellectual" propi, que fes oblidar els collaboradors rojos del passat. Les dues propostes es van fer plenament visibles en les commemoracions del 26 de gener, data de la liberación de Barcelona, quan Galinsoga convidava els "seus" amics (majoritàriament provinents del medi madrileny) a commemorar la "recuperació" de la ciutat per a la Nueva España. Gent com José M. Pemán, Francisco de Cossío, Manuel Machado, Joaquín Arrarás, Eduardo Marquina, etc., feien acte de presència, amb la voluntat de quedar-se com a nucli de referència inexcusable de la "nova" intellectualitat i el "nou" periodisme que havia portat la victòria franquista de 1939.

Paraules clau: Luis de Galinsoga, La Vanguardia Española, calendari franquista, intellectuals franquistes, Eduardo Marquina, José M. Pemán, Manuel Machado, Aurelio Joaniquet, Eugenio Montes, Wenceslao Fernández Flores, 26 de gener, memòria històrica.

Abstract: From the very moment that Luis Martínez de Galinsoga took control of the Barcelona based newspaper La Vanguardia (which, from the end of January 1939, went by the name La Vanguardia Española), he began a process of transformation within the newspaper, following official orders, that soon became visible in two areas: firstly, in terms of the paper's conversion into one of the most orthodox advocates of the celebration of the new Francoist calendar and, secondly, its at tempts to foster its own intellectual hub, which would serve to wipe out all memories of the 'Red' collaborators of the past. These two aspects became abundantly clear during the commemorations of $26^{\text {th }}$ January, the date of Barcelona's 'liberation', when Galinsoga invited 'his friends' (mainly from the Madrid press) to commemorate the 'reclamation' of the city by the New Spain. People such as José María Pemán, Francisco de Cossío, Manuel Machado, Joaquín Arrarás, Eduardo Marquina, etc., attended the event, with the intention of becoming the irrefutable leading hub of the 'new' intellectualism and 'new' journalism that had accompanied Franco's victory in 1939.

Keywords: Luis de Galinsoga, La Vanguardia Española, Francoist calendar, Francoist intellectuals, Eduardo Marquina, José María Pemán, Manuel Machado, Aurelio Joaniquet, Eugenio Montes, Wenceslao Fernández Flores, $26^{\text {th }}$ January, historical memory. 
Escuche quien quiera oírla | la historia tan singular | de Luis de Galinsoga | un castellano leal, | que marchó a tierra de moros | — catalanes, que es igual—, | al grito de «iViva España!» | queriéndonos desasnar.

Josep M. EsPINÀs i Néstor LujÁN, «Réquiem para un director», v. 1-8

En algunos lugares las fuerzas nacionales conquistaron, y en otras liberaron. Yo diría conquista de Madrid y liberación de Barcelona, aun más importante que conquistar era restaurar, restablecer, incorporar, entablar un diálogo en un idioma común.

Francisco DE Cossío, «Sentido de una liberación», La Vanguardia Española, 26 gen. 1943

El 19 d'abril de 1939, Josep Pla, teòric codirector de La Vanguardia Española - el seu company en la direcció, Manuel Aznar, havia aprofitat la mort de Pius XI per marxar a Roma i plegar, de fet, del càrrec al diari barceloní-, va fer reproduir a les pàgines del diari l'avís del seu collega de l'ABC de Sevilla, de quatre dies abans, on s'anunciava l'arribada a Barcelona de Luis Martínez de Galinsoga, en qualitat de nou director del diari del comte de Godó. ${ }^{1}$ Segons explicaria Josep M. Huertas molts anys més tard, l'arribada de Galinsoga a Barcelona culminava una operació una mica més complicada que la simple designació a dit pel «supremo jerarca de la Prensa», Ramón Serrano Suñer, en la qual va tenir un paper important Juan Ignacio Luca de Tena, propietari i director de l'acabat de recuperar $A B C$ de Madrid: per evitar la possibilitat que Galinsoga entrés en competència amb Luca de Tena al diari madrileny — amb l'argument que havia dirigit l'edició de Madrid just abans de l'esclat de la insurrecció militar i, per tant, tornava per recuperar el càrrec de director-, Luca de Tena va aconseguir - o recomanar, o suggerir...- que Ramón Serrano Suñer nomenés el seu subordinat director del diari del comte de Godó. ${ }^{2}$ Fossin els que fossin els motius que van portar Galinsoga a Barcelona, ben aviat es demostraria que havia estat un encert: el franquisme, en els seus moments inicials de construcció i desplegament al país, acabava d'incorporar una peça de primera categoria.

1 «Luis de Galinsoga, nuevo director de La VANGUardia Española», La Vanguardia Española, 19 abr. 1939.

2 Josep M. Huertas, Una història de La Vanguardia (Barcelona: Angle Editorial, 2006), 127. 


\section{Abans d'arribar a Barcelona: un record des de Sevilla}

El 14 d'abril de 1939, un dia abans que $A B C$ anunciés que Luis Martínez de Galinsoga marxava a Barcelona per fer-se càrrec de La Vanguardia Española, l'edició sevillana va publicar el primer dels seus articles commemoratius del 14 d'abril. Luis de Galinsoga encetava una pràctica que, de manera inexorable, aniria repetint un any rere l'altre, amb la missió i voluntat que el conjunt de la població no oblidés, per anys que passessin, de quines mans havia estat salvat pel Caudillo i les seves tropes. Sota el crit «iAcordaos...!", Galinsoga demanava —o, millor, exigia- extreure una «lección moral» que estimulés «la memoria de tantos y tantos papanatas de entonces, de tantos y tantos habilidosos de aquellos días, de tantos y tantos "conllevadores" aprovechados de aquel ludibrio bajo los más especiosos sofismas que culminaron en la gran paparrucha y retorcida perfidia del "régimen que España quiso darse"». Calia recordar cada dia i cada any perquè «la trágica alucinación» d'abril de 1931, que va desembocar «en la dantesca revolución soviética de 1936», no es tornés a repetir mai més: «En esta fecha del 14 de abril, primera que celebramos bajo el signo radiante de la victoria plena contra los enemigos de España y fundamentalmente contra la República que los aglutinó en el monstruoso maridaje del Pacto de San Sebastián, en esta fecha, evocar la enorme superchería histórica del 14 de abril, con su gigantesca estafa, al revuelo de unas elecciones concejiles, es tanto como conjurar, en una apretada y entrañable solidaridad, a todas las fuerzas vivas y vitales de la nación para el escarmiento, para el horror y para la santa ira contra el signo y la sustancia del 14 de abril. Contra ellos se alzó el 17 de julio de 1936, al mando del Caudillo, el Ejército glorioso que, bajo la República, agotó el sufrimiento de todas las humillaciones, de todos los vejámenes y de todos los escarnios; contra todo lo que el 14 de abril representaba de antiespañol, refrendado por las Internacionales consabidas, se alzó, en pos del Caudillo y el Ejército, la nación reivindicadora de sus destinos históricos imprescriptibles. Al cumplirse hoy los ocho años que nos separan, en abismal distancia moral, aunque en corto espacio cronológico, de la gran vergüenza y de la gran hecatombe, España, en posesión de la gallardía y de la eficacia triunfales que le deparó el Caudillo, con la gloria y el genio de su espada, 
se siente firme en su designio inquebrantable de reparar el ludibrio y la ruina que le fueron inferidos por la República y sus cómplices».

Era un digne comiat de Sevilla i de l'ABC que donava perfectament el to del personatge. Si una cosa positiva es pot dir de Galinsoga, és que no es va moure mai d'aquests paràmetres, que va ser d'una coherència absoluta. No ens ha d'estranyar, doncs, que Ramón Serrano Suñer, empès pels Luca de Tena - o motu propio, atès que tenia poder suficient per decidir pel seu compte-, l'enviés a Barcelona. No només li garantia un anticatalanisme furibund i paranoic, sinó que, més enllà d'aquest aspecte, seria també una peça central en el desplegament del nou ordre en un territori hostil, i un informador i transmissor de consignes de primera categoria. La recentment conquerida Catalunya necessitava un aprenentatge accelerat de «¿Qué es lo nuevo?», que diria José M. Pemartín, i homes com Luis de Galinsoga —en parallel al rescat de Luys Santamarina i la seva Solidaridad Nacional — eren indispensables.

Amb aquests paràmetres, Galinsoga — amo i senyor de La Vanguardia Española, amb el beneplàcit del seu propietari- va convertir el nou calendari franquista (18 de juliol, 2 d'agost, 1 i 12 d'octubre, 20 de novembre, 26 de gener, 1 d'abril, etc., les anomenades «fechas sagradas») ${ }^{3}$ en un argument informatiu i doctrinari de primera categoria. Eren una peça essencial per intentar construir una memòria històrica franquista a Catalunya, que permetés l'anorreament definitiu del passat republicà, separatista i revolucionari. Darrere la consigna, que es repetia en cada commemoració, «iAcordaos...!», hi havia la voluntat política d'amenaçar permanentment la població amb el retorn de l'infern si no assumia la inexorabilitat providencial de l'Alzamiento i la victòria del Caudillo. Naturalment, Galinsoga no actuava pel seu compte, a títol individual. Ell era una peça essencial d'un programa polític d'estat, destinat a generar una memòria pròpia i en el qual es van invertir diners, personal i mitjans en quantitats ingents, i que tenia com a finalitat la destrucció no només de la memòria republicana, sinó també de la història política, cultural i social dels anys trenta espanyols. En aquest aspecte, «el nuevo calendario trata de borrar, de reemplazar una época precedente, el período republicano democráti-

3 Santos JuliÁ, «Memoria, historia y política de un pasado de guerra y dictadura», dins Santos JULIÁ, dir., Memoria de la guerra y del franquismo (Madrid: Taurus, 2006), 37. 
co - acusándole de traicionar las ideas patrióticas y de representar "la invasión de las ideas extranjeras", el marxismo-y de sustituirla por una "nueva era"».4

Abans d'installar-se a Barcelona, però, des de «la hermana» Sevilla, Galinsoga va saludar la caiguda de la ciutat, seguint l'ortodòxia del discurs franquista. En homenatjar a Torcuato Luca de Tena, recordava que «la prosperidad y [...] el honor de Barcelona» estaven vinculats «a la vida y el honor de la Patria unida».5 Ara era el moment d'«hacer más estrecho, más íntimo y más cordial el abrazo con los hermanos a quienes hoy redime el Caudillo. Fuera de esta hermandad española, excéntrica a ella, están todos los que fraguaron la ruina y el envilecimiento de las provincias catalanas; verdaderos extranjeros, en efecto, porque tenían sus negras almas vendidas a la traición internacional, que quería especular sobre la posesión de esas provincias de España». Fora de la unitat amb Espanya no hi havia res, només misèria. Però havia guanyat el Caudillo, «y en la hermandad, insertos en ella con cuantos matices se quiera de su alma nativa, pero alma española fundida en la clara progenie nacional, están todos los catalanes que en este momento confirman su fe jurada y cumplida o hacen profesión de ella con el alma encendida en sinceridades de amor a España en su unidad y en su totalidad, sobre todas las cosas, sin mezcla de frivolidad o de desvío». ${ }^{6}$

L'endemà reblava el clau de la «conquista» 0 , més dit, del «rescate».7 Amb la caiguda de Barcelona, «la España unida y en orden» incorporava

4 Josefina Cuesta, La odisea de la memoria. Historia de la memoria en España. Siglo XX (Madrid: Alianza, 2008), 153 i 197.

5 Siul [Luis De GalinsogA], «"Hermanos o extranjeros”, $A B C$, 27 gen. 1939.

6 En parallel a Galinsoga, algú va arrodonir les explicacions sobre la campanya de Catalunya i la caiguda de Barcelona («Barcelona por Franco, primer estratega de la época», $A B C, 27$ gen. 1939): «El objetivo militar y político de la campaña de Cataluña está logrado. Barcelona, florón de la Historia Patria, realidad mediterránea en el concierto universal, exponente de la grandeza de un pueblo prócer, ha vuelto a España. | Portento castrense, que ha conmovido al mundo, realizado por el primer estratega de nuestro siglo. Hasta en las gargantas de locutores franceses, que fueron esquivos, cuando no adversarios, el nombre de Franco vibraba ayer con acentos admirativos. Era la verdad de nuestras bayonetas imperiales, refulgente al sol de la justicia y de la razón. | Barcelona, rescatada, será el hecho culminante de la guerra redentora; caso inédito en el Arte militar. No hay antecedentes en los tratados. | Entre el Segre, el Ebro y el Llobregat se ha escrito una nueva página de Historia, por España y por la permanencia de los eternos valores de su fe cristiana. No habrá pluma capaz para trazar la adecuada exaltación del gran suceso; cuando sobran emociones faltan palabras».

7 Siul [Luis De GalinsogA], «Nada menos que provincias de España», $A B C, 28$ gen. 1939. 
«estas provincias suyas [...] a la geografía política y espiritual [...] después de su frenética aventura separatista, en la que si no hubo una generalidad de autores directos, no dejó de haber multitud de cómplices y especuladores en la traición...». Més endavant, afirmava amb rotunditat que «ya nunca dejarán de ser provincias de España — nada más y nada menos que provincias de España- esas tierras catalanas en donde se sembró la maldición y la ruina mediante el fermento que sería grotesco si no hubiera sido trágico, de las supercherías diferenciales y de las ridículas piruetas de nacionalidad». I ho acabava amb un llarg paràgraf, que definia perfectament l'estil del personatge i avançava allò que podrien llegir a Barcelona aquells ciutadans que continuessin fullejant La Vanguardia Española: «Provincias de la España imperial. Provincias de estirpe nacional auténtica y no máscaras con cetro de caña en un minifundista ámbito en el que se jugaba a las viejas farsas del Parlamento, de la República, de la Democracia, y de la "autodeterminación de los pueblos". ¿Qué buen catalán que ame a su provincia podrá sentirse tan indigente en sus aspiraciones que se contente con que Cataluña fuera una minúscula y cómica parodia de un Estado regida por un lunático o por un pistolero? Ser provincia, en cambio, de España, saberse gobernada como las demás provincias, es un honor que colma las mejores ambiciones patrióticas de cualquier espíritu dotado de dignidad y aun de orgullo, pero, sobre todo, de cualquier espíritu inteligente. [...] Esto es lo que ha salvado a los catalanes de la muerte y de la ruina fulminadas por la Cataluña independiente que soñaron los delirantes, los criminales o los imbéciles».

L'inconvenient d'aquests articles, del 27 i 28 de gener de 1939, era que havien estat escrits a Sevilla, no a Barcelona. Eren extremament útils per als lectors d' $A B C$ de la zona franquista, però no arribarien a la població catalana. Per tant, quan Galinsoga aterrés a Barcelona per fer-se càrrec del diari del comte de Godó, la commemoració i la celebració de la liberación de la ciutat hauria de prendre una altra volada, molt més impactant, visible i cridanera.

A més d'això, la commemoració de la liberación tenia un triple valor que no s'havia d'oblidar: la liquidació de la capital del separatisme català, l'esclafament de la ciutat obrera i revolucionària, i la caiguda simbòlica de Catalunya. Encara que, en termes militars, el país no hagués estat completament ocupat fins al 12 de febrer — amb el tancament de la bossa 
del Coll d'Ares; el 10, les tropes franquistes havien tancat la frontera a La Jonquera - la caiguda de Barcelona va certificar el que tothom sabia: el principi de la fi de la guerra en territori català.

\section{0: la primera oportunitat}

L’any 1940, Galinsoga es va poder estrenar en la commemoració de la liberación de Barcelona. Era el primer any que podia donar la benvinguda a l'aniversari del rescate des del mateix escenari, en directe, cara a cara amb els veïns de la ciutat. L'any anterior, a Sevilla, el ressò de les proclames havia estat llunyà. Era el moment d'ensenyar totes les cartes i posar tots els arguments sobre la taula dels catalans. Era el moment que aquests donessin la benvinguda al primer any de «paz fecunda» de què gaudia Espanya, una Espanya «redimida de la ignominia, de la ruina y la muerte que fue para ella la República». ${ }^{8}$ El text no estava signat i inaugurava una pràctica molt estesa en els anys següents: Galinsoga - l'autor de l'article, sense cap mena de dubte -9 parlava en nom del seu gremi, del diari que dirigia i de l'empresa que comandava el comte de Godó. Des d'aleshores, La Vanguardia Española, com a empresa i mitjà de comunicació, expressaria el goig de la victòria de manera sistemàtica al llarg del nou calendari franquista. Luis de Galinsoga, amb el laissez faire del comte de Godó, va portar el diari a la més estricta i absoluta obediència al dictador i al sistema polític que el sustentava. Era, en certa manera, visualitzar la plena integració en el franquisme, la incorporació a la Nueva España d'un diari rescatat de les urpes dels rojos, que assumia plenament les funcions que els vencedors atorguessin a la premsa i, a la vegada, es presentava com el mascaró de proa del franquisme a Catalunya. No aconseguiria, però, ser la plataforma principal dels franquistes catalans més illustrats; aquesta funció va quedar a mans de Destino. Per als falangistes purs i durs, i el funcionariat en general, ja els valia Solidaridad Nacional.

Amb tot plegat, el recordatori del primer aniversari de la liberación tindria un regust especial. Naturalment, el fet de ser el primer ho justificava,

8 «Ante el primer año de la paz fecunda», La Vanguardia Española, 2 gen. 1940.

9 Difícilment algú altre hauria pogut començar l'article d'aquesta manera: «Ha de trascender de la acostumbrada ritualidad formularia nuestra actitud al ver trasponerse el año 1939, para dejar paso, en el curso impasible de los días y palpitante de la Historia, al nuevo de 1940", Ibid. 
però hi havia alguna cosa més a banda de deixar enrere la guerra. Com s'escriuria a La Vanguardia Española el 2 de gener, «descontados, naturalmente, los tristes años rojos, que transcurrieron bajo un signo de dolor y de miseria, es indudable que Barcelona hacía muchísimos años que no había festejado la entrada en el Nuevo Año con el desbordante y vivo regocijo que se desbordó a raudales en nuestra ciudad el domingo por la noche». No podia ser d'altra manera, si hom tenia en compte que en aquell «año de la Victoria», les funcions religioses «revistieron con mayor motivo extraordinaria solemnidad y esplendor».

Ja des del primer any van quedar dibuixats els grans pilars argumentals sobre els quals s'aixecaria la commemoració: la gratitud al Caudillo i a l'Exèrcit, en una lectura molt restrictiva de quins eren els integrants fonamentals del projecte franquista; l'obligació de recordar, i una mica de doctrina política per a uns ciutadans que, durant dos anys i mig, havien viscut segrestats i, per tant, sense possibilitats de conèixer la nova doctrina. En el primer i segon cas, els arguments podien ser incorporats en un mateix text. Gratitud i record anaven de la mà, tant a l'hora d'homenatjar l'Exèrcit, com en el reconeixement de l'Auxilio Social: «Que con las glorias, queremos decir con la habitualidad del goce de la liberación, no se nos vayan las memorias. Que no se nos embote el deber de la gratitud en la rutina de la normalidad recobrada. No olvidemos jamás aquellas jornadas primeras de la Barcelona redimida, pero todavía famélica y extenuada, sobre las que pusieron la emoción de su celo y de su eficacia las blancas manos piadosas del Auxilio Social». ${ }^{10}$

Hi havia, doncs, una memòria del curt termini, dels anys de la guerra o de les «jornadas primeras de la Barcelona redimida»; però no era exactament la memòria de la història que volien elaborar Luis de Galinsoga i els seus amics. La memòria immediata s'alimentava del contrast entre el domini roig i la redempció de la liberación i, a vegades, era feble. Ho assenyalava Raimon d'Abadal i Calderó en el seu dietari: «Els records són un xic apagats. Les dificultats de l'hora, fatals després de quasi tres anys de destruccions i salvatgisme, pesen sobre tothom i són molts els que no re-

10 «Gratitud imperecedera a Auxilio Social», La Vanguardia Española, 26 gen. 1940. 
corden prou els sofriments que patiren fins ahir va fer un any». ${ }^{11}$ Això era el record dels temps recents. El franquisme volia anar una mica més enllà i oferir els continguts del que seria «la memòria de la història» certa, no només dels anys de la República, sinó dels orígens del terror viscut, la llunyana Setmana Tràgica de 1909. Per tant, calia fer memòria de moltes coses, més enllà del 14 d'abril de 1931:

De las bandas terroristas que, hace cuarenta o treinta y cinco años, sembraban a diario la muerte de una manera alevosa e impune en las calles de nuestra ciudad.

De las procacidades también impunes y también aleves de los aventureros a sueldo en los libelos para difamar el honor militar.

De los sacrilegios, saqueos y asesinatos de la semana sangrienta de 1909 con sus «jóvenes bárbaros» inolvidables.

De los trabucaires en las encrucijadas, dueños y árbitros de la vida de los transeúntes.

De los forajidos que asaltaban la Administración municipal y provincial para lucrar infames cohechos, de perpetua recordación en los anales del pillaje y de la aventura.

De los «contratistas de la tranquilidad pública» que lucraban precio vil para regular a sus antojos el crimen.

De la Universidad degenerada en laboratorio de un sedicente y necio separatismo parapetado tras los pechos de una juventud alucinada.

De la Generalidad con sus grandes sayones y su delincuencia común erigida en oligarquía.

De la fiera roja ululando por las calles en persecución de sus víctimas inocentes.

Del incendio o el colapso de tantas y tantas industrias y de tanto comercio como se empobrecieron en los años de la República para venir a su total ruina bajo el signo caótico del soviet separatista.

Del hambre de los años rojos, en cuyos últimos meses nos alimentamos hasta con hierbas inmundas.

11 Ramon D’Abadal i CAlderó, Dietari de guerra, exili i retorn (1936-1940) (Barcelona: Publicacions de l'Abadia de Montserrat, 2001), 393. 
De las noches en tinieblas en nuestras Ramblas y en nuestras grandes avenidas, mientras la muerte paseaba en trágica zarabanda sus espectros prendidos en las pistolas y en los fusiles de los milicianos asesinos.

De nuestras madres, de muestras mujeres y de nuestras hijas, harapientas y famélicas, en cuyas pupilas se reflejaba el terror y en cuyas carnes hacía presa cuando no los escarnios soeces de los patibularios, las manchas hórridas y las pústulas asquerosas producidas por la avitaminosis.

De los trágicos «paseos» y de las checas dantescas.

EN SUMA, de una Barcelona sovietizada y arrancada al seno de España bajo el signo de una maldición.

BARCEloneses: De todo esto nos redimió el Caudillo con un precio sublime: el de la sangre de nuestra mejor juventud.

¡Acordémonos siempre, barceloneses...! ${ }^{12}$

¡Quaranta anys de terror! L'experiència històrica no era reduïble als anys republicans, incloent-hi la guerra. L'origen de tot calia trobar-lo en el fatídic final del segle xIx, en el punt més baix de la decadència espanyola. Era aquí on començaria la reflexió franquista sobre el passat del país, l'autèntica «memòria històrica» de la dictadura i els seus homes. Després, en un equilibri a vegades una mica precari, es tractaria de combinar el deute i el deure de recordar — el terror roig, la gratitud al Caudillo, etc.amb la tasca de fer memòria - fer història - del passat: quan va començar tot i com es va arribar a 1939.

La proposta de La Vanguardia Española oferia altres elements interessants; per exemple, la denúncia del «soviet separatista», una expressió feliç per denunciar un assumpte que es tendia a arraconar: la confluència de bolxevisme i separatisme en el camp de batalla. Era una barreja poc habitual; La Vanguardia Española, com el Diario de Barcelona o El Correo Catalán, sempre insistia en el caràcter separatista dels anys republicans. El lema «Ha llegado España» era més un avís de caràcter nacionalista, que no pas el full de presentació d'un programa nou, que eradicaria l'obrerisme anarquista i comunista — per tant, la lluita de classes_- en favor de l'Espanya falangista dels «productores». Ara, la imatge del «soviet separatista» feia pensar que no s'havia oblidat del tot la vessant contrarevolucio-

12 «Barceloneses, jacordémonos!», La Vanguardia Española, 26 gen. 1940. 
nària de la proposta franquista-falangista, que se sintetitzava en la imatge de l'aliança entre separatistes i comunistes - o anarquistes. Sintètic i concentrat, el manifest en pro de recordar recollia els aspectes essencials del que havia estat - a ulls dels franquistes, evidentment - un passat tenebrós que no arrancava l'any 1931 o 1936, sinó que remetia a una mena de pecat original, comès en dates tan transcendents com el 1898 o el 1909.

En la primera commemoració de la liberación, la doctrina política va venir de la mà d'Aurelio Joaniquet, un veterà monàrquic de la línia més dura, tinent d'alcalde de l'Ajuntament de Barcelona i Consejero Nacional de FET y de las JONS, un càrrec que molts monàrquics, alfonsins o carlins van considerar perfectament compatible amb la seva visió tradicional del món, a la qual el falangisme responia amb una mirada pretesament revolucionària i profundament menyspreadora d'aquella «vella classe dirigent». Però el franquisme ja les tenia, aquestes paradoxes, que convertien un bon monàrquic en un dirigent francofalangista, però amb aspiracions de restauracions règies.

Explicava Aurelio Joaniquet que, un any després de la liberación, ja es podia fer un primer balanç, una passada de comptes davant «los ciudadanos de Barcelona», ${ }^{13}$ però no a la manera equivocada de la democràcia, sinó tenint en compte els nous paràmetres: «Hijos de un régimen jerárquico y autoritario, antitético el concepto rusoniano del Gobierno, no tenemos nuestro origen en el pueblo, pero le debemos al pueblo sacrificio y servicio, según el credo de Falange Española Tradicionalista». I continuava, més precís: «Militantes de la auténtica doctrina política, que se basa en el concepto católico de la vida, no nos debemos al pueblo en el sentido democrático y liberal de la palabra, pero nos interesa mucho vivir en contacto con el Pueblo, en el sentido integrador y ordenado». No era una afirmació massa clara, però sí que s'entenia que «el Pueblo» era el receptor passiu i agraït de l'ingent esforç que havien dut a terme «los que entramos el día 27 de enero en esta ciudad desolada y afrontamos la tarea de devolverle su vida, su fisonomía y su temple, sin alharacas, embustes y fanfarrias democráticas». La nova/vella classe dirigent s'havia installat, de nou, al capdavant «del Pueblo» i assumia la responsabilitat

13 Aurelio JoAniquet, «Balance», La Vanguardia Española, 27 gen. 1940. 
de dirigir-lo, sempre respectant el sentit jeràrquic del nou sistema i, per tant, seguint les consignes emanades del Caudillo.

\section{1: «moralejas muy aleccionadoras» $\mathbf{i}$ «meditaciones ascéticas muy severas»}

Si la commemoració de 1940 va tenir un cert to de sobrietat, o de contenció, l'any següent, el gener de 1941, Luis de Galinsoga va treure al carrer bona part del seu repertori doctrinal. D'entrada, per exemple, va tenir cura que tots els seus subordinats al diari saludessin la població en uns termes taxatius: «La Redacción de LA VANGUARDiA, [...] integrada hoy, gracias a Dios, por españoles auténticos y no por la analfabeta caterva de forajidos que hace dos años y un día aun consumaban el escarnio de estas páginas, se siente especialmente capacitada para esa meditación a que invitamos a todas las conciencias honestas. Por experiencia, este periódico sabe el abismo de catástrofe material pero, sobre todo, de ruina moral, de indignidad y ludibrio que representó la República para todo lo español». ${ }^{14} \mathrm{El}$ fet és que la salutació dels «españoles auténticos» que formaven la redacció del diari aquell gener de $1941^{15}$ estava vinculada a una molt extensa i intensa reflexió que proposava La Vanguardia Española als seus lectors. Molt probablement, la «meditación» era obra de Luis de Galinsoga, tot i que no signava l'article, però l'estil era el seu. Començava amb una reflexió de context, en la qual el segon aniversari de la liberación de Barcelona havia de ser motiu de «moralejas muy aleccionadoras y [...] meditaciones ascéticas muy severas». És a dir, menys falses alegries i més tenir en compte que España «y, por lo tanto, las provincias catalanas y entre ellas Barcelona - esencia, atributo y gloria irrevocables de la unidad nacional - caminan angustiosamente por lo más desolado y áspero de este invierno calamitoso de 1941 con el que Dios quiso poner a prueba, nuevamente, el temple de la fortaleza de un pueblo al que la tragedia

14 «Meditación en el aniversario», La Vanguardia Española, 26 gen. 1941.

15 La nota permetia entendre que el diari - sota l'atenta mirada del poder públic corresponenthavia completat el procés depurador intern i havia fet fora el darrer sospitós de formar part de «la analfabeta caterva de forajidos» d'abans de 1939. En parallel, en aquells moments ja estava en marxa la guerra entre el comte de Godó i Gaziel, amb el creuament d'expedients de responsabilitats polítiques i sumaríssims militars (en el cas de l'antic director del diari). 
circundante de la guerra internacional adolece con aflicciones y penurias». Així com l'any anterior, la guerra europea —o més ben dit, la drôle de guerre, la guerra estúpida entre Alemanya, França i la Gran Bretanyano havia estat mencionada per enlloc, el 1941 la situació era força diferent: França havia caigut estrepitosament; la Gran Bretanya encara estava sotmesa a bombardeigs massius i a l'amenaça de la invasió, i Alemanya i Itàlia semblaven les grans vencedores.

Per tant, era natural que aquesta vegada es recordés que, fora d'Espanya, el món estava en guerra: «las circunstancias de la guerra europea fueron apretando el dogal y estrechando el cerco, hasta casi estrangular nuestra biología económica, harto traumática después de la Guerra Civil. Sería una inmensa necedad y un sarcasmo histriónico que en estos días de evocaciones y de recuerdos perpetrásemos la simulación de que todo es paradisíaco, bonancible y feliz en las circunstancias que rodean el segundo aniversario de la histórica proeza benemérita de liberar a Barcelona». L'alegria per la liberación no podia tapar les dificultats de l'hora, dificultats exteriors, naturalment, derivades de la guerra a Europa.

Però feta aquesta advertència de context, era el moment de l'avís amenaçador, un recurs que Galinsoga utilitzava amb una extrema generositat: «existe [...] una infamia en cierta deliberada y sospechosa amnesia que tiene brotes virulentos e inconfesables en conciencias de gentes bien avenidas con la paz de Franco y con la liberación de Barcelona, para el logro de sus dividendos y para la especulación de sus negocios, sólo para eso. Y es también sobremanera oportuno que en nuestras meditaciones de este día dediquemos una reflexión a semejante crimen imponderable, latente en el fuero del pensamiento, ya que en el de la acción o siquiera en el de la ostentación lo hace imposible la condición alevosa, solapada e hipócrita de quienes lo perpetraron». ${ }^{16}$ Era un salt qualitatiu important: un dels grans portaveus del franquisme a Catalunya no es conformava

16 Naturalment, Luis de Galinsoga no era l'únic a amenaçar i a denunciar traïdories ciutadanes. El seu company de professió José Bernabé Oliva, cap de l’Asociación de la Prensa, censor i depurador de periodistes, també recollia la notícia d'aquestes actituds inacceptables: «Pero los rojos, y especialmente los rojillos, a quienes la magnanimidad de la justicia de Franco y su inmerecida condición de españoles habían liberado del aplastamiento implacable; y los "patriotas crematísticos", que se habían sentido distanciados de la subversión marxista por las meras lecciones infligidas a sus intereses materiales; quienes notaron que su conciencia patriótica se aflojaba inconcebiblemente ante el simple temor de que sus inteligencias umbilicales decayeran fláccidas, comenzaron a sentirse inquietos 
amb els crims visibles, materials. Tal com s'afirmava en el Proyecto de Ley de Responsabilidades Políticas (Réplica a las observaciones formuladas por distintos Ministerios), Luis de Galinsoga - i els seus camarades, civils i militars - tenia molt clar que «el pensamiento delinque», ja que defensar la idea «que cuando se siembran entre las masas idearios perniciosos mediante la propaganda o la actuación, sólo se ha de reparar el daño, cosecha inevitable de tal siembra, sin castigar ésta de ningún modo, equivale a afirmar que se debe sancionar el efecto y dejar impune la causa, lo que constituye una enorme inconsecuencia del más puro sabor liberal». Portat al terreny de la Barcelona de 1941, volia dir: tots aquells ciutadans que pensaven en termes no patriòtics i s'atrevien a dir-ho, encara que fos en els cercles més íntims i privats de la seva confiança, eren uns criminals: pel fet de pensar-ho i atrevir-se a dir-ho. Possiblement, Galinsoga tenia al cap les dades que li arribaven dels informes policials i falangistes: bona part de la població estava desillusionada per la manca de resultats positius en la reconstrucció de postguerra i l'ambient aliadòfil era molt més estès del que agradava als franquistes.

Pel que feia al «Pueblo» — dit a la manera d'Aurelio Joaniquet—, a Galinsoga no el molestava massa; el seu objectiu central eren els burgesos catalans desagraïts, poc participatius en el projecte franquista, desconfiats i, en definitiva, egoistes, que havien agraït al Caudillo haver recuperat els seus negocis, però després resultava que murmuraven, es queixaven en veu baixa i, per acabar-ho de rematar, aquell any 1941 es mostraven més favorables a una improbable victòria aliada, que no a l'evidència de la puixança del feixisme. Sempre hi havia una ocasió per a aquesta mena d'advertències i Galinsoga no era home que les desaprofités.

Però en la commemoració de 1941 encara hi va haver temps de recuperar un altre dels grans arguments franquistes de 1939 - i, fins i tot, dels anys anteriors - , un dels pilars interpretatius utilitzats per explicar què havia succeït en els anys republicans a Catalunya i qui n'era el responsable. La tesi central es podia resumir en l'expressió «el segrest de la Catalunya espanyola pel catalanisme», la qual era compartida per falangistes i franquistes catalans - conjunturals o permanents - i servia per expli-

y solapadamente, con odiosa clandestinidad, bisbisearon, murmuraron y mascullaron, demandando la luna», «Glosa, en la fecha magna. La espada, nuestra guarda», Diario de Barcelona, 26 gen. 1941. 
car els darrers quaranta anys del país d'una manera molt clara: «Entre los ludibrios que Barcelona y que Cataluña tuvieron que arrostrar a cuenta de los suplantadores de su genuina representación, estuvo aquel tan infamante de presentar a nuestra ciudad y a nuestras provincias bienamadas, sino como groseramente agresivas contra él según los abusos y los desmanes de aquellos años infaustos del larvado separatismo que habían de desembocar, para expiación de muchos, y para ruina de Barcelona y de Cataluña, en las epilepsias criminales de la Generalidad y el Estatuto. Cautivo de una minoría intrépida, cínica y maleante, el pueblo de Barcelona y el pueblo catalán tuvieron que absorber la amargura y la vergüenza de verse representados muchas veces ante el resto de España por los aventureros, los delincuentes y los cursis, de diversos estilos y en diversas etapas, pero en el fondo movidos todos por la infamia de la misma traición separatista». ${ }^{17}$

«Cautivos de una minoría» resumia prou bé el punt de coincidència de La Vanguardia Española, els falangistes i, per exemple, el jove monàrquic Santiago Nadal, que també havia explicat que alguns burgesos del país van prendre consciència «de que bajo la capa del catalanismo habían pasado un cuarto de siglo haciéndole el juego a la revolución y contribuyendo por mucho a hacer posible su triunfo»; ${ }^{18}$ eren aquells joves de famílies catalanes que «querían llamarse en alta voz españoles», però a qui «el catalanismo de derechas y de izquierdas», que «controlaba estratégicamente todos los centros de la actividad», no els deixava respirar en llibertat. ${ }^{19}$

Les commemoracions de la liberación de Barcelona anaven prenent una volada cada vegada més destacable. Luis de Galinsoga, al capdavant de La Vanguardia Española, va tenir molt clar, des d'un bon començament, que eren una ocasió única per adoctrinar la ciutadania. Naturalment, l'1 d'abril, el 18 de juliol o l'1 d'octubre també eren dates obligades i aprofitades, però el 26 de gener — com la resta del mes i els primers dies de febrer per a les altres ciutats del país - era un esdeveniment que atenyia directament als barcelonins i, per extensió, a la resta de catalans. Per tant, la doctrina destillada des del poder i els seus portaveus tenia un

17 «Gratitud... y desagravio», La Vanguardia Española, 28 gen. 1941.

18 Santiago NADAL, «La burguesía del alma huera», Destino 119 (28 oct. 1939).

19 Santiago NADAL, «Los que siempre se llamaron españoles», Destino 82 (25 oct. 1939). 
contingut especial, dirigit de manera molt precisa a una societat que havia d'assumir uns missatges molt concrets: el «segrest de Catalunya» en les dècades anteriors, la poca i mala memòria de certs grups socials, etc. Aquest era el cànon fixat, que seria ampliat i millorat en els anys següents.

\section{2: a l'ombra de la visita del Caudillo i del nou ordre europeu}

L'any 1942, l'aniversari de la liberación de Barcelona va tenir un convidat excepcional: el Caudillo. ${ }^{20}$ El Generalísimo, el «Caudillo invicto», «glorioso libertador de Barcelona», etc., no havia tornat a Catalunya des de la desfilada triomfal del 21 de febrer de 1939, quan «el pueblo, fundido en devoción y en emociones al Ejército vencedor, aclamó frenéticamente al Caudillo y a sus tropas» (La Vanguardia Española, 22 feb. 1939). Un parell d'anys després de la victòria, el general Franco tornava a Barcelona per fer un primer balanç de la situació. Naturalment, el desplegament mediàtic va estar a l'alçada de l'episodi històric: els diaris van dedicar pàgines i recursos - fotografies, collaboradors, etc. - a cobrir la visita, i les consignes van brotar com els bolets a la tardor. La més important: recordar, fer memòria, tenir present, no oblidar ni el 26 de gener de 1939 ni el que havia passat abans ni el que havia succeït després. No era una consigna nova, però sí que era una gran ocasió per reblar el clau de la nova memòria franquista: «Recordemos. Recordemos. Recordemos... Que en el recuerdo está la mejor defensa contra todos los blandengues o malintencionadas interpretaciones de la realidad presente, contra todos los derrotismos y contra todas las especulaciones infames de una larvada traición contra España». ${ }^{21}$ De fet, des de la commemoració de gener del 1940, la primera amb Galinsoga al capdavant del diari, que la consigna central era aquesta: recordar i no oblidar.

Però, juntament amb la lletania de l'obligació de recordar, l'aniversari de 1942, reforçat per la visita del Caudillo, va permetre a Galinsoga oferir una explicació d'un altre criteri ja aplicat, però no explicitat, des de 1940: «He tenido especial cuidado en que ninguno de los colaboradores de LA

20 «La noticia más grata para Barcelona. El Caudillo honrará la ciudad presidiendo los actos conmemorativos de su liberación», La Vanguardia Española, 21 gen. 1942.

21 «Deuda de gratitud al Caudillo. La transfiguración de Barcelona», La Vanguardia Española, 24 gen. 1942 . 
VANGUARDIA que integran ese concertante para cantar hoy la gloria y la eficacia españolas de Barcelona, sea barcelonés ni siquiera catalán. Deliberadamente he prescindido, aunque sintiendo en mi torno todo el vacío que la privación representa, de las firmas ilustres que componen el cuadro de colaboradores catalanes de LA VANGUARdia. Hoy tiene que hablar el periódico sin voz catalana. ¿Por qué? Porque el homenaje a Barcelona tiene que estar henchido de conocimiento y amor, pero también de aquella autorizada e irrecusable imparcialidad que le atribuye el hecho de que sean voces y acentos diversos de la España unida quienes canten a la eficacia y la gloria de Barcelona y de Cataluña españolas». ${ }^{22}$ De fet, Galinsoga mentia una vegada més: no havia comptat mai amb gairebé cap de les plomes catalanes del moment, excepte Ferran Valls Taberner, Josep M. Tallada i Josep M. Junoy i, potser, algú més. Eugeni d’Ors també participava del privilegi, però era tota una altra cosa. Molt poca gent, en efecte, però havia estat una opció deliberada des que va aterrar al diari la primavera de 1939. Ell havia jugat la carta d'importar la veritable intellectualitat franquista, la de Madrid, perquè a Barcelona no n'hi havia, o era de segona categoria o havia estat contaminada, en algun moment o altre de les seves vides, pel catalanisme o qualsevol altre dels enemics doctrinals de la Nueva España. La visita del Caudillo, l'any 1942, havia estat l'excusa per fer-ho públic, però la idea estratègica ja s'havia començat a desenvolupar tres anys abans.

Sobre aquestes dues columnes - el record permanent de la liberación i els seus múltiples significats, i el fet evident que la intellectualitat veritable de la Nueva España era a Madrid, no a Barcelona-, Luis de Galinsoga va continuar alimentant la seva particular política de la memòria, que hauria de ser el discurs canònic sobre allò que va ser Catalunya i Barcelona abans de 1939, quin va ser el significat real de la victòria i què es va començar a guanyar a partir d'aquell moment. I, sobretot, que calia recordar, sempre i a tota hora; oblidar, fer-se el distret, era un delicte moral i un insult polític. Mai com en aquells anys i amb aquella gent, la memòria va ser una obligació, un deure, un imperatiu patriòtic. I com que dels catalans no se'n podien fiar, caldria deixar en mans amigues de la Nueva España aquest deure de memòria.

22 Luis De Galinsoga, «Los hombres y los días. Mi tributo», La Vanguardia Española, 25 gen. 1942. 
La memòria d'allò que havia succeït i el record que se n'havia de tenir no eren patrimoni de ningú —més ben dit, eren patrimoni del conjunt dels vencedors, però no d'una facció concreta. Tots hi podien dir la seva i recordar el que volguessin o poguessin, sense sortir dels límits de l'ortodòxia franquista. Tenir memòria, haver conegut o patit el fatídic passat roig, donava una superioritat moral a l'hora de situar-se en els nous paràmetres del present: «Conocimos los horrores y el ludibrio de la mixtificación, del desmán y del cautiverio ignominioso bajo la chusma republicana y estamos, por tanto, en perfectas condiciones de apreciar, aunque no seamos capaces de lograr llamarla, toda la medida del reconocimiento que debemos al Caudillo». ${ }^{23}$ La tesi de l'article era interessant, perquè excloïa d'aquest procés de coneixement i valoració tots aquells catalans que, a partir de l'estiu de 1936, havien fugit cap a les zones controlades pels rebels o, sobretot, s'havien quedat en països amics - Itàlia, França, Gran Bretanya, etc. - i els còmplices i els responsables de «los horrores y el ludibrio». Qui quedava, doncs? Quedaven els fidels, franquistes, falangistes i carlins que mai no van dubtar del Caudillo i la seva victòria des del primer moment, que havien donat la seva vida i havien patit tortures i persecució a la zona roja per defensar la causa nacional. Potser eren pocs, però eren els escollits i els més sincerament agraïts. A Galinsoga no li interessava el poble, la ciutadania en general. Ell buscava les noves elits burgeses i aristocràtiques, civils i militars — i també eclesiàstiques -, que havien de donar el to a la nova situació. I en aquesta recerca de les noves classes dirigents, també incloïa els intellectuals, els homes del nou pensament, de la nova cultura i de la nova/vella llengua.

Tota commemoració havia de tenir una poesia de referència, una dedicatòria literària. L'Espanya franquista era terra de poetes, que infectaven tota mena de pàgines de la premsa del moment. Gairebé cada diari tenia una pàgina literària, almenys en els primers anys de la postguerra, on s'oferien primícies poètiques i d'altres menes. En aquest aspecte, Solidaridad Nacional era el model de referència, amb una pàgina setmanal dedicada a publicar poesies en honor del Caudillo, José Antonio i altres caídos, a la División Azul i a les passades glòries imperials espanyoles. La Vanguardia Española era un diari sobri i seriós, com volia remarcar el seu di-

23 «La Vanguardia Española a su Caudillo», La Vanguardia Española, 25 gen. 1942. 
rector, i no dedicava massa espai a aquestes frivolitats. Però sempre tenia un racó per als grans dies de la Nueva España; aleshores, es convidava un poeta admirat i reconegut, que aplicava el seu ofici i inspiració a cantar la data assenyalada. En el cas del 26 de gener de 1942, l'home escollit va ser Manuel Machado. Fervent catòlic i persona d'ordre i amant de les velles tradicions, el poeta andalús era l'altra cara de la moneda del seu germà, màrtir, heroi i icona de l'Espanya republicana a l'exili i de l'antifranquisme clandestí. Com el seu germà Antonio, Manuel era un poeta conegut, popular, que no deia mai que no a la premsa, a ser a prop del poble. En el seu debut barceloní, Manuel Machado va regalar als lectors una mena de lletania sense cap mena d'interès estilístic, però que resumia molt bé els paràmetres principals de la nova història d'Espanya vigent en aquells anys. Vist d'una altra manera, semblava una versió en vers de la Historia de España contada a los niños, del seu amic José M. Pemán. La lletania era molt simple. Invocava la ciutat de Barcelona i li anava afegint petits comentaris, que servien per vincular-la a aquesta nova història: «costilla de Ebro», «celtíbera y romana», «cristiana», «primera corte visigoda», etc. Passava per ser "perla y emporio del Mediterráneo», "puerto y boca del Renacimiento español», «fabril y mercante», i plena de «catedrales y máquinas», etc. Tot plegat era un enfilall de tòpics, que culminava de manera solemne: «sintió, como nunca, el año 39, tal día como hoy, la suprema gloria de ser española por los siglos de los siglos. ¡Ayer, hoy y mañana!». Era molt poca cosa i d'una qualitat ínfima, però ja feia el fet. Barcelona tenia el seu poeta i el seu poema de la liberación; i ni el primer era de la ciutat, ni el segon s'escapava de la línia marcada. Davant d'això, davant del potencial del diari, era molt difícil que propostes indígenes, com la dels falangistes catalans de Solidaridad Nacional, es poguessin imposar o, senzillament, tenir un lloc digne en la nova cultura i la nova memòria.

Molt més sòlida i interessant era la collaboració d'Eugenio Montes, un dels personatges centrals de la «corte literaria» de José Antonio, pes pesant del nou poder cultural i intellectual, i amb bons contactes en els ambients catalans. Montes era una signatura freqüent en els mitjans barcelonins i Luis de Galinsoga el tenia com un dels seus collaboradors habituals. A «Cataluña de ayer y hoy» (25 gen. 1942), Eugenio Montes volia ser una mica original i exposar una hipòtesi pseudohistoricista, que permetés entendre el desastre català; la pregunta fonamental era: «¿Cómo 
un pueblo dotado de tantas virtudes individuales ha podido caer en graves pecados colectivos?». La resposta: «Cataluña ha sido la región española que ha vivido con más empeño y más fortuna los modos de ser del siglo XIX europeo, sus ideales y sus realidades, sus teorías y sus prácticas, que lo demás de la nación no quiso ni supo dejar o aclimatar». Catalunya, és a dir, Barcelona, es va emmirallar en París i Londres; Barcelona va voler ser una ciutat europea, «en contraste con el Madrid tumbón, andrajoso y chistoso del ochocientos». Què va sortir malament? On es van equivocar? Catalunya «no advierte las tremendas mudanzas que trajo el siglo $\mathrm{xx}$ »; i la més fonamental d'aquestes «mudanzas» era el desmuntatge de l'Estat liberal, dèbil per naturalesa, per substituir-lo per un de diferent, de «gran poderío», que posaria remei a la «flaqueza peligrosa» de l'Estat democràtic. Entendrien, els lectors del diari, que Montes estava parlant de l'aparició dels feixismes com la gran alternativa als decadents i dèbils Estats liberals? Els darrers paràgrafs de l'article eren força clars i dibuixaven perfectament el panorama de començament de 1942: l'arribada del feixisme per la porta d'Espanya - el Madrid que no havia estat contaminat pel segle XIx europeu - i la seva extensió, a partir de la guerra, amb la incorporació - parcial - catalana a la seva causa i l'accés a una «Europa en génesis», l'anomenat nou ordre europeu. Era un recorregut net, gairebé sense obstacles, en què els punts de partida i arribada estaven perfectament definits: de «las tremendas mudanzas que trajo el siglo Xx», passant per «la ideología de la nueva época española», fins a «una España asomada al cambiante Mundo, a los fastos y los nefastos de una Tierra que da vueltas y a la vez gira en torno a luz sin fatiga».

Melchor Fernández Almagro, un dels historiadors oficials del moment, home prolífic i demanat per la premsa de postguerra, també tenia coses a dir. Sobretot recordava les dues dates fonamentals: «El azar de las cosas quiso que nos sorprendiera en Barcelona el 14 de abril de 1931. ¡Tremendo día aquél!... Cierto es que en cualquier punto de España las heces sociales fueron removidas y agitadas hasta salir a la superficie, ensuciándolo todo, y que la plebe se apoderó de los tranvías, de los camiones, y hasta de los árboles, para enracionarse, con podrido júbilo. Quedaba así marcado el augurio de lo que la República había de ser. Cómo se llegó, en efecto, al final temerosamente previsto, no es cosa que ahora hayamos de puntualizar. Pero ese proceso de descomposición llenaba todas nuestras medita- 
ciones, pasados apenas ocho años, mientras marchábamos desde Burgos, cabeza de España a la sazón, a Barcelona, recién recuperada: 26 de enero de 1939: he aquí otra fecha memorable. Pero de signo contrario: la demoníaca energía del veneno exigió la costosa triaca de guerra. Y la Barcelona recuperada para España conservaba aun, en letreros e inscripciones de toda índole, el tatuaje de su doble esclavitud: social y política. La lucha de clases había sido de proporciones extraordinarias, y, bajo la discordia de anarquistas y marxistas, el trabajo vivió en servidumbre cruenta. Políticamente, la unidad del Estado y de la Patria había sido herida a fondo. No de un solo e impensado golpe, por supuesto. El separatismo había hecho su camino a través de no pocos años, favorecido por la mala fe de unos, tanto como por la estúpida papanatería de otros. Hasta que sobrevino la prueba caldaria». ${ }^{24}$ Naturalment, la culpa de tot plegat era el segle XIX, com ja havien assenyalat Eugenio Montes i la resta de plomes ortodoxes de la dictadura. De fet, el mateix Caudillo hi dedicaria un parell de reflexions força importants. ${ }^{25}$

24 Melchor Fernández Almagro, «Emoción de la unidad en Barcelona», La Vanguardia Es pañola, 25 gen. 1942.

25 Per exemple, uns mesos més tard d’aquest 1942, en plena celebració del 18 de juliol: «Una vez más he de recordarles, a los buenos españoles, que venimos padeciendo las consecuencias de un siglo de liberalismo que ha impreso en la sociedad española y especialmente en la de Madrid, donde la farándula política tenía su centro, unos vicios y costumbres incompatibles con la seriedad de los pueblos modernos», «El Jefe del Estado proclama ante el Consejo Nacional la Ley de creación de las Cortes Españolas», La Vanguardia Española, 18 jul. 1942. Uns mesos més tard, el desembre, ja es remuntava a 1789 per trobar l'arrel dels mals del segle xx: «Somos actores en una nueva era, en la que ya no podemos discurrir con la mentalidad de antaño. El pensamiento de España no puede retroceder al siglo XIX, maldito por tantos conceptos. | Yo pediría a los españoles abandonen los viejos prejuicios liberales y se asomen a los balcones de Europa para analizar la historia de los acontecimientos contemporáneos. | Nosotros no pertenecemos a un mundo distinto del europeo, aunque poseemos características propias y reservas de espiritualidad para asombrarle.|Todos aquellos acontecimientos nos demuestran que estamos asistiendo al final de una era y al comienzo de otra. | Sucumbe el mundo liberal, víctima del cáncer de sus propios errores, y con él se derrumba el imperialismo comercial, los capitalismos financieros y sus millones de parados. La felicidad ofrecida por la Revolución francesa se había trocado en el "hombre mercancía", en las competencias comerciales, con sus jornales míseros y sus masas de desamparados. El incremento de la riqueza no fue acompañado de su distribución equitativa, y una parte importante de la humanidad viene debatiéndose contra las nuevas formas de las miserias humanas. | Sólo se es libre cuando no se está esclavizado por la necesidad. | Los tópicos marxistas, hábilmente explotados, prendían en las masas por cuanto representaban un cambio de la situación imperante y una engañosa promesa de justicia. | El mundo liberal, al especular con los votos, les creó la conciencia de su propia fortaleza, y entonces se inició el proceso revolucionario que las distintas coyunturas se encargan de precipitar», Discurso del Caudillo ante el III Consejo Nacional (Madrid: Ediciones de la Vicesecretaría de Educación Popular, 1942), 5-7. 
Però Fernández Almagro anava una mica més enllà i invocava un dels arguments centrals de l'ideari falangista - adoptat, per altra banda, per franquistes de tota mena i condició-: el «segrest d'Espanya» a Catalunya. Tot plegat era degut a un fenomen que es remuntava a cinquanta anys enrere: «el contubernio de las falsas solidaridades», «la gestión desembozada del extremismo antiespañol», responsables de «la situación horrenda del período en que Barcelona y Cataluña vivieron, o fueron muriendo, huérfanas de España. El secuestro iniciado por la Generalidad pudo consumarse, con ocasión de la Guerra Civil, si no hubiese alcanzado Franco la victoria». I la victòria franquista havia significat «la unidad» en tots els àmbits imprescindibles: «lo político, lo social, lo jurídico, lo sentimental».

No era massa freqüent presentar la guerra - la Cruzada - com una llarga batalla en dos fronts: el nacional, de la «Unidad de la Patria» i el social de la lluita de classes; una guerra, doncs, contra la revolució social, és a dir, el comunisme. Per exemple, el periodista Francisco de Cossío, un altre dels puntals intellectuals dels mitjans franquistes, defensava la batalla per la «unidad nacional» com a únic motor de la guerra: «Durante tres años terribles, España estuvo dividida, y aun pudiéramos decir partida, y fue la entrada en Cataluña del Ejército nacional lo que conmovió más profundamente los anhelos unitarios, ya que Cataluña representaba, en la política que nos llevó al desastre, el punto culminante de la disidencia». ${ }^{26}$ L'assumpte era relativament senzill: quan Espanya havia tingut problemes, havia de trobar-ne l'arrel en la pugna entre la «disgregación» i la «reintegración». No hi havia res més.

Un altre dels amics de Luis de Galinsoga era l'escriptor Wenceslao Fernández Flórez. Era habitual trobar-lo a les pàgines de La Vanguardia Española al marge de qualsevol commemoració i, com César González Ruano i altra gent del mateix perfil, havia descobert l'ocasió de posar un peu a la Barcelona intellectual sense que ningú no pogués oposar-s'hi. En el seu cas, Fernández Flórez recordava l'arribada a Barcelona, quan va poder comprovar «el terrible descenso de la gran ciudad durante el período marxista. [...] Fábricas paradas, riqueza destruída, comercio e industria en ruinas, suciedad... Barcelona, más que ninguna otra capital de España, nos aleccionaba acerca de las consecuencias acerca de la mentira comu-

26 Francisco DE Cossío, «El signo de la unidad», La Vanguardia Española, 25 gen. 1942. 
nista». Tot plegat, venia de lluny, d' «una interpretación demasiado literal y candorosa de aquel concepto de Igualdad proclamado por la Revolución Francesa. [...] Spengler escribió que el comunismo es el régimen político de la Envidia. Y no suelen ser los mejores quienes abrigan en su alma ese pecado mortal, sino los inferiores, los impotentes y los fracasados». Efectivament, continuava escrivint, «el marxismo aniquila al hombre, lo substituye por una comunidad amorfa, en la que los estímulos naturales están mal suplidos por la más feroz de las violencias; impone el trabajo como un fin. Y bajo su dictadura, esa magnífica ciudad, orgullo de los hombres, que es Barcelona, se mustió, se empequeñeció, se hizo sucia y hambrienta y mezquina. Fue el más claro y convincente de los ejemplos». ${ }^{27}$

Ernesto Giménez Caballero, el prolífic escriptor feixista, també es va trobar una ciutat «exánime», amb «puertas sin sirenas», «calles sin almas», «calles putrefactas de andrajos y mondaduras», per on caminaven «piojos humanos, parásitos... Manos sucias y horribles que se nos tendían en silencio por pan, por caridad, por un pitillo». La conquesta de Barcelona era el tancament d'una ferida que sagnava des del 18 de juliol de 1936, sinó d'abans. El 26 de gener, Espanya va ocupar una ciutat que, a causa d' «una voladura histórica», «un separatismo a cercén», ${ }^{28}$ havia estat a punt de perdre's sense remei.

Marcat el nivell de les collaboracions i amb el dictador a la ciutat, Luis de Galinsoga i els seus homes es van encarregar d'anar destillant doctrina en els dies següents. Hi havia una mica de tot: l'estil galinsoganià en estat pur, que assenyalava al «barcelonés bien nacido que en el día de hoy no sintiese la emoción de su gratitud, más fuerte que él mismo, para aportarla como un homenaje alícuota en el total e indiviso homenaje al Caudillo», ${ }^{29}$ o l'allusió a «El verbo del Caudillo» com a programa i declaració d'intencions i actituds. «La palabra del Caudillo», escrivia probablement Galinsoga, «se modula regida por una disciplina mental que es también rigurosamente militar», «no es palabra, sino expresión de ideas y de sentires que todos llevamos en el alma». Si no s'entenia malament a

27 Wenceslao Fernández FlóreZ, «Lo que iba con las tropas», La Vanguardia Española, 25 gen. 1942.

28 Ernesto Giménez Caballero, «Memoria al 26 de enero. Camisa y boina en Barcelona sobre una criatura», La Vanguardia Española, 25 gen. 1942.

29 [Sense signar], «España en las calles de Barcelona», La Vanguardia Española, 27 gen. 1942. 
Galinsoga - i, moltes vegades, no era fàcil captar el significat del que escrivia-, volia dir que el Caudillo llegia les ments dels seus súbdits i després parlava; era un fenomen sobrenatural.

Però el diari no oblidava el contrast entre l'abans i el després, la restauració dels bons costums i la reconstrucció de les velles glòries. La presència del Caudillo a l'Ajuntament, per exemple, va permetre que la casa s'hagués purificat «en la resurrección de sus viejos esplendores»; enrere quedaven els temps en què «no solamente las procaces garras de la bestia roja, sino las taimadas maneras de los ladrones de guante blanco habían creado un clima de delincuencia y de picaresca indecentes. En ese clima las dalmáticas, las mazas, los candelabros, los tapices hubieran sido atributos falaces de una profanación inverecunda». ${ }^{30}$ Era exactament el mateix que havia succeït amb el Palau de la Diputació, on «han vuelto los señores [...], liberado, como Barcelona entera, de la tiranía procaz de los facinerosos». ${ }^{31}$ Era el retorn al vell ordre, però de la mà d'un geni que hi veia més enllà. A La Vanguardia Española no hi havia proclames falangistes, ni crides a suposades revolucions; diari burgès i dretà per excellència, saludava la restauració del vell ordre social, rejovenit, dinamitzat pels nous temps que acompanyaven la gegantina figura del Caudillo.

\section{3: Eduardo Marquina i la reivindicació dels quintacolumnistes}

1943 va ser l'any d'Eduardo Marquina. Luis de Galinsoga li tenia un afecte especial - de fet, el franquisme literari en general li'n tenia-, probablement perquè el poeta era una prova vivent que la llengua castellana havia sobreviscut a l'hegemonia literària, cultural i lingüística del català - i del catalanisme - del primer terç del segle xx, i s'havia reviscolat amb el rescate de Catalunya l'any 1939. Per al director de La Vanguardia Española, Eduardo Marquina — com Jacinto Benavente, Manuel Machado, José M. Pemán i tants d'altres en àmbit espanyol - demostrava que la Nueva España també tenia els seus escriptors i intellectuals, que no forçosament s'havien criat en el món falangista, sinó que tenien unes trajec-

30 [Sense signar], «Esplendor y austeridad dignos del huésped», La Vanguardia Española, 27 gen. 1942.

31 [Sense signar], «Desagravio i gloria del Palacio provincial», La Vanguardia Española, 29 gen. 1942. 
tòries més extenses en el temps. Davant de l'eclosió dels nous intellectuals - sobretot falangistes: Dionisio Ridruejo, Antonio Tovar, Pedro Laín Entralgo, Rafael Sánchez Mazas, Juan Beneyto, Juan Aparicio, etc.; però també franquistes sense més ni més: Melchor Fernández Almagro, Francisco de Cossío; aristòcrates lletraferits, etc.-, Marquina era el lligam amb un passat llunyà i heroic, viscut i sobreviscut a contracorrent de les hegemonies esquerranistes i separatistes.

Era, doncs, l'hora d'un Eduardo Marquina que havia d'aprofitar la conjuntura: desapareguts els intellectuals de referència —exiliats, depurats, morts o en silenci-, el camp estava ple d'oportunitats per als qui s'havien sentit marginats, silenciats en els anys anteriors; i Marquina era un d'ells. El poeta de vella arrel modernista —en llengua castellana, això síes va presentar als lectors barcelonins amb un «Recordatorio» ${ }^{32}$ de la seva trajectòria personal i, a la vegada, del retorn a Barcelona. Hi explicava el poeta que el darrer any de la guerra el va passar a Sevilla, amb la seva família i envoltat de «muchos barceloneses y catalanes», que s'havien deslliurat «de particularismos» i es reconeixien «unidos por una empresa común». En aquells temps de guerra, «el egoismo se avergonzaba de su esterilidad. Cundía, con la prodigiosa eficacia de un clima o de una sazón, el poder milagroso de la fe colectiva. En la hoguera de la guerra, lo individual quemaba sus culpas».33 Naturalment, si la guerra es feia per salvar Espanya de rojos i separatistes, la primera cosa que s'exigia als catalans que es refugiaven a la zona rebel era la seva completa renúncia a qualsevol forma de «singularització», començant, evidentment, per la llengua.

Confortat amb aquesta solidaritat, Marquina va viatjar a Barcelona «poco tiempo después de su liberación». Hi arribava amb por del que trobaria, del que li recordarien els amics: «Persecuciones, privaciones, raptos de muda alegría cuando, al rumor tronante de los aviones nacionales, sin desconocer el peligro de muerte, se arrodillaba el corazón porque España estaba cerca; los consuelos fugaces de aquel sacerdote que pasó, inolvidable; tal misa oída en circunstancias de milagro, con la agravante heroica de un riesgo, que hoy se bendice; la clandestinidad inefable de la presencia de Dios Nuestro Señor Sacramentado en el hogar de alguno;

32 Eduardo Marquina, «Recordatorio», La Vanguardia Española, 26 gen. 1943.

33 Ibid. 
y siempre y en todos, aquella única, idéntica, repetida, esperada y esperanzadora delicia patética del Parte del Generalísimo, saboreado a gotas, por la Radio, con el mismo ritual, bajo la manta, entrañas adentro de la noche». ${ }^{34}$ Semblava el retrat del bon quintacolumnista, que hauria pogut signar un protagonista d'aquells anys com Manuel Tarín Iglesias. ${ }^{35}$

Misses clandestines, connexions amb les ràdios enemigues, emocions pels bombardeigs - com que no es podia parlar de bombardeigs, es feia servir un eufemisme: l'aparició de l'aviació franquista (o alemanya, o italiana), presagiava la propera liberación-, converses amb els camarades amagats o empresonats, etc., tots eren aspectes d'una mateixa vida de rereguarda, sacrificada a la causa de l'Alzamiento.

Però no només hi havia un «Recordatorio». Eduardo Marquina també advertia, perquè la invocació a recordar tenia una segona part: avisar la població d'allò que va ser i que, per les debilitats humanes, podia tornar. A més d'això, el poeta no podia desentonar del missatge general del diari i del seu director: vigilar, recordar i avisar; o, fins i tot, amenaçar. Per tant, ell també hi havia de dir la seva: «Si aun quedan almas incapaces de entrega, o si alguna ha decaído, lamentable, del impulso inicial, a su intención principalmente se renuevan los fastos vividos y se calienta la voz en el grito de las efemérides. La Cruzada fue río de fuego sobre zarzas de egoísmo, que no volverán a retoñar. Para el camino en común, al que disiente o se reserve, trabando la marcha, hay que apartarlo con el pie»..$^{66}$ Marquina no podia ser més clar i més coherent amb un dels arguments centrals dels discursos franquistes. La victòria de 1939 era foc nou per cremar «zarzas de egoísmos» velles; era trist que, quatre anys més tard, encara s'hagués de recordar, però aquesta era la missió dels mitjans i dels seus homes: recordar i avisar.

L'altra gran aportació d'aquell any va ser l'article d'Eugenio Montes, l'acadèmic falangista habitual a la premsa barcelonina, sobretot a $\mathrm{La}$ Vanguardia Española, titulat «Cuando la paz floreció...», i que es publicà, també, el 26 de gener. Montes no es limitava al recordatori de les gestes passades, les virtuts de la liberación, etc. Ja feia temps que estava interes-

34 Ibid.

35 Vegeu Manuel TARín IgLEsias, Los años rojos (Barcelona: Planeta, 1985).

36 Marquina, «Recordatorio». 
sat en un assumpte cabdal: la vinculació entre la Nueva España i el nou ordre europeu que s'havia començat a albirar després de la caiguda de França, el juny de 1940, i anava prenent forma en les llunyanes terres de l'est europeu, a mesura que Alemanya avançava, de manera implacable, en direcció als Urals i el mar Caspi. L’any 1942 ja havia ofert una mostra d'aquesta literatura en el pròleg al llibre de Carles Sentís La Europa que he visto morir, ${ }^{37}$ on remarcava els encerts de l'obra, però retreia a l'autor que hagués tancat el llibre sense parlar de la nova Europa que els alemanys i els seus aliats estaven construint.

Tot l'article de La Vanguardia Española era d'allò més interessant, ple de doctrina ortodoxa. El primer punt: l'allargament de la guerra espanyola, amb l'esperança que coincidís amb l'inici del conflicte que s'albirava a Europa. Era la coneguda tesi del doctor Juan Negrín estrafeta i manipulada: «los dirigentes enemigos, sabiéndola perdida [la Guerra Civil española], prolongaron desesperadamente el suplicio de España con la esperanza de durar hasta la guerra mundial. De ahí el encono en la batalla del Ebro y las órdenes de Negrín con su crueldad moscovita». ${ }^{38}$ Sortosament, «Franco salvó la independencia española, ganando con Barcelona los meses precisos para interponer distancia entre un conflicto y otro».

Certament, el Caudillo havia evitat —ell tot sol— la terrible trampa que el doctor Negrín havia preparat; però no significava que la Nueva España, allunyada del perill de ser arrossegada a la guerra europea, es desentengués de la situació continental. Al contrari, Espanya hi era i no hi era; havia actuat com a «adelantada» — «como ocurrió en América», precisava Eugenio Montes-, amb la qual cosa «nuestro pasado no coincide exactamente, en su movimiento y su compás, con el paso europeo. Vamos por el mismo camino y a la misma meta, pero con andar diferente». El missatge era clar: la Nueva España volia participar del repartiment del botí de la nova Europa, però no com una aliada més d’Alemanya, una subordinada a la nova potència continental, sinó en la seva qualitat de precursora, d'«adelantada», de primer país europeu que havia derrotat el comunisme. En paraules falangistes, «el destino de España, aunque en gran medida participa del destino común de Europa, posee un "tempo"

37 Carles Sentís, La Europa que he visto morir (Madrid: Editora Nacional, 1942).

38 Eugenio Montes, «Cuando la paz floreció...», La Vanguardia Española, 26 gen. 1943. 
y un modo de cuidar que no puede decirse de ningún dato ajeno».39 Els estrangers havien d'entendre dues coses fonamentals: la primera era la via espanyola al feixisme, singular, catòlica, nacionalista i reaccionària; la segona, que l'espai vital espanyol no era a Europa, era a l'Àfrica, en dura competència amb l'imperi colonial francès. Per tant, Espanya «fara da se», com deien els feixistes italians de l'època, faria per ella mateixa en un nou marc de referència continental.

Eugenio Montes s'havia escapat una mica de la commemoració estricta de la liberación de Barcelona, però si el resultat d'aquell fet històric havia estat evitar l'arrossegament d'Espanya a la guerra europea, calia dir-ho ben clarament. Darrere d'això, venia l'explicació pedagògica, necessària enmig de tanta confusió, sobre la geopolítica espanyola de 1943, quan el futur europeu, i mundial, encara era obert.

Eugenio Montes, però, venia acompanyat de dos camarades més: Francisco de Cossío i Felipe Sassone. El periodista castellà reconeixia obertament que la guerra havia tingut un to antiseparatista inqüestionable; era el que en deia «un matiz que de la esfera política pasaba al sentimiento nacional».40 I encara anava una mica més lluny quan situava «el carácter religioso y nacional de la contienda» com l'element central de tot plegat: «A favor de la corriente del Frente Popular, en aquel conglomerado que incitaba a todas las confusiones, los separatistas de estas dos regiones [Cataluña y Vizcaya] prestaron a la contienda un carácter especial, y, del otro lado, dieron a la Cruzada una significación evidente de reconquista». Efectivament, va ser una guerra de «reconquista», que va permetre «ahogar el separatismo en su ofensiva más criminal y desatentada».

Però Cossío no es quedava en el pla general; escrivia sobre allò que havia viscut i afirmava sobre experiències contrastades. Quan va entrar a Barcelona i Bilbao - perquè va tenir «el honor» de participar de les dues «liberaciones»—, va comprovar «la alegría que este hecho [la liberación] produjo en los buenos españoles», no «la malsana alegría de una revancha, sino el contento sano que en el pasaje bíblico produce la llegada del hijo pródigo». En aquest aspecte, l'ortodòxia del periodista era modèlica:

39 Ibid.

40 Totes les citacions de Francisco DE Cossío, «Sentido de una liberación», La Vanguardia Es pañola, 26 gen. 1943. 
Espanya, la Nueva España, havia arribat com el fill pròdig, per rescatar la terra catalana —o basca- de les grapes separatistes. A Barcelona, explicava, hi havia arribat en plena nit: «Toda la ciudad estaba iluminada, pero desierta, y con el primer catalán que pude hablar fue con un sereno, un clásico sereno barcelonés, con su chuzo y su farolillo, que encontré en la Plaza Universidad. Aquel hombre sencillo, quien aceptó con verdadera alegría un cigarro, que se convirtió en un paquete, pues no tenía sino unas cuantas colillas en una cajita de latón, me dio la primera versión de la vida barcelonesa durante el dominio rojoseparatista. Después, en días sucesivos, fui recogiendo el dolor de los buenos catalanes; unos, engañados; otros, arrepentidos; y otros, víctimas de la terrible persecución que en esta ciudad tuvieron los disidentes». Els «buenos catalanes» es varen retrobar amb la resta d'espanyols, amb els quals van poder mantenir «un diálogo en un idioma común». Amb tot això, però, no s'havia d'oblidar; l'oblit podia «volvernos a un pasado siniestro». Debilitar el record era un atac a l'essència de la missió bèllica dels insurrectes: «La España nacional ganó la guerra precisamente por esto, por haber encontrado la fórmula de unidad que apretaba en un anhelo común a todos los españoles agrupados en torno de Franco».

Com Francisco de Cossío, el poeta peruà Felipe Sassone - un altre collaborador habitual del diari- també cantava el rescate de Barcelona. Després de recordar l'estada a la ciutat, que li va permetre fer amistat amb Santiago Rusiñol, escriure poemes a la maragalliana i descobrir el modernisme literari, encara li quedava un tros de paper per dedicar-li uns versos:

Cataluña a vosotros retorna, a Madrid dando aviso ejemplar... Sobre España una alada Victoria va planeando en vuelo final. Es la nueva victoria de Cristo, cruz y espada, piadosa y tenaz, que rejunta, rehace y renueva de savias antiguas la España inmortal.41

41 Transcrit dins de l'article de Felipe SAssone, «Evocación y nostalgia», La Vanguardia Española, 26 gen. 1943 . 
En honor a la veritat, cal reconèixer la sinceritat de l'autor quan confessava que havia perpetrat «unos pobres versos que improvisara torpemente»;22 però, què més podia dir l'insigne poeta, que recordava el Poble Espanyol de l'Exposició de 1929 com «la maravilla de España, que llegaba de la mano de Barcelona, fragante como una novia, al beso salado y azul del Mediterráneo»? La liberación feta - horrible- poesia.

Eduardo Marquina, en el seu article, havia mencionat —o suggeritla vida que havien portat «los buenos catalanes» afins al franquisme. ${ }^{43}$ Efectivament, no es podia oblidar els quintacolumnistes que havien lluitat a la rereguarda, que havien passat perills i riscos: alguns d'ells havien mort en plena batalla; d'altres havien patit la detenció a les sinistres txeques del SIM - Félix Ros, literat falangista de moda en aquells anys, ho havia recordat en un text gairebé clàssic i canònic, Preventorio $D-; 4$ altres encara, com Francisco Lacruz, Gabriel Avilés, etc., havien fet memòria de les seves activitats clandestines, que calia recollir en el marc de la commemoració de la liberación. L'encarregat de fer-ho va ser Luis Fontes de Albornoz, un falangista de l'aparell del partit, militant devot de l'organització que, a partir de 1943, es va convertir en collaborador habitual de La Vanguardia Española, i en un dels comentaristes polítics més prolífics dels difícils anys de la postguerra. En la seva condició de veterà quintacolumnista, era un testimoni privilegiat dels temps heroics i de la duresa de la vida clandestina així com de l'oposició als republicans i esquerranistes:

En los últimos meses de 1938, el Servicio de Información que organizamos desde las primeras jornadas de julio de 1936 pasó horas muy graves. Toda la red de nuestros agentes había sido intervenida por las organizaciones enemigas, y si bien no habían éstas logrado la identificación personal, ni conseguido la detención de ninguno de los comprometidos nuestros hombres tenían, sobre el riesgo mortal de su descubrimiento, el desaliento de su momentánea ineficacia. Del mismo modo sufrimos por entonces la amputación de nuestros mejores medios de comunicación con la España nacional y la amenaza directa contra el cuartel general del Servicio, varias veces hallado y otras tan- 
tas escapado providencialmente en el último momento. Las documentaciones falsificadas que encubrían a los más activos y mejores de los nuestros se nos quedaron invalidadas, y, en fin, todo se nos aparecía descoyuntado, en trance de peligrosa y dificilísima compostura. En algún otro lugar hemos relatado cómo conseguimos hallar definitivo asilo, y basta para el objeto de hoy decir cómo en tan dramática coyuntura nos ocurrió el expediente de acudir en demanda de instrucciones a las autoridades nacionales y poner, con entera y redoblada franqueza en sus manos, la dirección de nuestra confusa actividad futura, solicitando de ellos incluso el consentimiento para renovar la composición de todo el Servicio.

Ya en alguna otra ocasión agentes nuestros habían atravesado la frontera francesa, llegado a Burgos y retornado a Barcelona. Mas en esta hora la misma situación nos evidenciaba que el juego no podría repetirse, y así acudimos a persona de excelente situación política y de indudable confianza para que en cierta ciudad de la costa atlántica francesa se entrevistase con uno de los jefes nacionales de nuestro Servicio y recogiera de él las inspiraciones que esperábamos para reanudar las actividades de la información. Cumplió nuestro hombre el difícil encargo, y a su regreso, exactamente el día 26 de noviembre de 1938, nos transmitió la confidencia recibida: No era necesario establecer nueva organización ni suspender la labor que habíamos proseguido con éxito durante más de dos años, sino mantenerse con los salvados restos más numerosos y bien trabados de lo que en un principio pudimos suponer, y aprestarse a la acción definitiva: aun nos añadió textualmente: «De un momento a otro comenzará la ofensiva contra la Cataluña roja, y en el plazo máximo de dos meses Barcelona estará liberada».

Toda la difícil apariencia de las circunstancias hostiles se nos resolvió entonces en fe. Tuvimos desde aquel momento la exacta sensación de que vivíamos los últimos días de opresión, de aquella opresión casi fisiológica, prescriptiva, asfixiante, que nos confinaba en los más inverosímiles lugares y que nos hacía mirar sin reconocimiento el milagro incesantemente renovado del sol. Barcelona fue liberada justamente el día que se cumplían dos meses de aquellas palabras que nuestro fondo íntimo, en ese recoveco rebelde a toda consolación, desconfiado y tenaz, juzgaba optimista con exceso. El episodio observado hoy desde la lejana perspectiva de una situación incomparable, revela cual y cuan profunda era la confianza nuestra en las autoridades de la Es- 
paña auténtica y cómo reputábamos todo esfuerzo, todo sacrificio, fecundos para el feliz término de nuestra obra final. ${ }^{45}$

Sense cap mena de dubte, era una de les millors reivindicacions - $\mathrm{i}$ recordatori- de la cinquena columna falangista a la rereguarda catalana. I era, a la vegada, una reivindicació necessària en uns moments que semblaven difícils per als falangistes, sobretot els camisas viejas: no acabaven d'aconseguir el reconeixement que es mereixien; havien hagut de compartir somnis i poders amb altres elements de la coalició contrarevolucionària; no eren el punt central, el focus, de la Nueva España; vivien, almenys a Catalunya, amb la comoditat de ser vencedors de la guerra, però a la vegada amb el disgust d'haver de compartir la victòria i els seus privilegis. No era una mala idea recordar a tothom que els falangistes es van jugar la vida - $\mathrm{i}$, en ocasions, la van perdre - per «la fe» $\mathrm{i}$ «la victoria», sobretot «en este tiempo de hoy, cuando las tensas amenazas han desanudado su gesto». ${ }^{6}$ Potser reflectia, Fontes de Albornoz, les incerteses d'una dura postguerra que començava a ser massa llarga? Potser el problema era que la revolució nacionalsindicalista no acabava d'arribar? Potser, amb tot plegat, calia marcar territori i jerarquia perquè, ja se sabia, la memòria és feble i els records es perden.

I la veu del diari?, la posició institucional, oficial, de La Vanguardia Española? Mantenint i ampliant la pràctica dels anys anteriors, Luis de Galinsoga va carregar el diari d'articles, signats o no, que feien el paper de declaracions oficials del mitjà. Aquesta era una pràctica habitual en el sistema mediàtic franquista, entre voluntària i obligada per la censura oficial, però Galinsoga la va perfeccionar de manera molt notable. L’any 1943, l'opinió del diari es va concentrar en dos articles no signats i un text de Galinsoga. En el primer cas («La victoria con creces», 26 gen. 1943), els dos punts centrals eren el balanç de quatre anys de liberación i la consigna de sempre: no oblidar. Pel que feia al balanç, l'assumpte no es podia limitar a la fi de la guerra, sinó que calia recular en el temps; l'autor — probablement, el mateix Galinsoga - feia una enèrgica crida als ciutadans

45 Luis Fontes de Albornoz, «Desde la catacumba heroica», La Vanguardia Española, 26 gen. 1943.

46 Ibid. 
perquè reconeguessin allò que «ven hasta los ciegos»: «el balance entre el abismo insondable de ludibrio y de caos, de hambre bíblica y de crimen infrahumano que representaban los años rojos y aun su natural antecedente biológico, los años de la República separatista, el contraste entre todo aquello, sima espantosa y dantesca, y la dignidad pública cuando no el auge positivo de hoy», era una veritat incontrovertible, indiscutible, que només els cecs - per tant, la gent més recalcitrant, obtusa i, en definitiva, perillosa - no veien.

Darrere d'això venia, naturalment, la gran consigna. Aquest any, de nou, no es podia oblidar «el juramento de que no olvidamos el 26 de Enero de 1939, porque aquella fecha representa para todos y cada uno de nosotros el rescate de nuestro honor, que vale mil veces más que nuestra vida y que nuestro pan nutricio». ${ }^{47}$ És clar que qui afirmava l'obligació de recordar abans que disposar de «nuestro pan nutricio», molt probablement no tenia problemes amb el proveïment de productes d'alimentació. ${ }^{48}$

A més a més, Luis de Galinsoga oferia les explicacions pertinents sobre l'aspecte del diari en aquelles jornades; dit de manera molt senzilla, La Vanguardia Española recollia «temas del espíritu y temas de la materia», «la armonía perfecta» per reflectir els nobles sentiments de la ciutat en la commemoració de la seva liberación. Del costat dels «temas de la materia», el diari va recollir articles d'Emilio Pellicer («El Puerto de Barcelona, liberado y reconstruido. Cuatro años de vida portuaria», 26 gen. 1943); de S. B. Bollar («Potencialidad de Barcelona en la industria y el comercio. Balance económico de cuatro años», 26 gen. 1943), que aprofitava per clavar una bona cossa al «regionalismo mal entendido» — «Los problemas económicos de España han perdido, por fortuna, aquella limitación mezquina impuesta por un regionalismo mal entendido, y adquiere anchura de tipo nacional»—, i de Francisco de A. Garrigó («De la Barcelona de aquel día a la Barcelona de hoy», 26 gen. 1943), que feia un entusiasta homenatge a l'Ajuntament de Miquel Mateu i Pla per la feina feta en

47 [Sense signar], «La victoria con creces», La Vanguardia Española, 26 gen. 1943.

48 Un home ben alimentat amb «el pan nutricio», com era Alfonso Sala, comte d'Egara, també insistia en el mateix: calia recordar el 26 de gener, «fecha gloriosa en los anales de nuestra Historia». Aquell dia significava per a la ciutat «la caída de un régimen de oprobio, de vergüenza, de ignominia y de vileza que comenzara el mismo día en que se proclamó, en España, su segunda y nefasta República», «La liberación», La Vanguardia Española, 26 gen. 1943. 
aquells quatre anys, que havia salvat la ciutat «de la situación ruinosa en qué se encontraba como consecuencia de la anárquica gestión municipal durante el período rojo».

I què millor que tancar l'any 1943 amb un «tema del espíritu» tan exemplar com un poema de José M. Pemán? Encara que fos literàriament dolentíssim, Pemán, amb Marquina, Jacinto Benavente i Manuel Machado, era una de les potes fonamentals del cànon literari de Luis de Galinsoga; un cànon molt limitat, certament, però molt illustratiu de les intencions i obsessions del director del diari. José M. Pemán, monàrquic autoritari, que venia de l'extingida Acción Española, era un bon exemple per demostrar que tots els falangistes eren franquistes, però que no tots els franquistes eren falangistes. Hi havia també un racó important per als defensors de la Monarquia tradicional i catòlica. Luis de Galinsoga, que era d'aquesta corda - mentre això no fos contrari a la seva devoció parareligiosa pel Caudillo-, ho tenia present a l'hora de fer lloc als seus amics en les dates assenyalades. El poema començava amb un lament:

¡Qué tres eneros sin rosas

los tres eneros que España pasó sin ti, Barcelona! ${ }^{49}$ (v. 1-3)

«Se muere España de pena» (v. 11), continuava, i ploraven el Duero, Cazorla, el Guadalquivir... A Espanya li faltava «aquel brazo | con que tocaba la lira» (v. 15-16). Però va arribar el 26 de gener i Espanya es va sentir complerta, «sana y entera, | como un verso concluido» (v. 29-30). El poema no donava per gran cosa més, però feia la funció que li havia estat assignada. Els barcelonins - i, per extensió, els catalans - havien d'aprendre el nou cànon literari i polític, i havien d'entendre que havien estat rescatats d'un desastre incommensurable, que la seva liberación era també la curació d'Espanya. No podien ser agents passius d'una gesta històrica; no els havien alliberat perquè fossin millors que els altres. José M. Pemán els ho explicava amb un poema: l'amputació havia estat contrarestada i Barce- 
lona tornava a ser espanyola. Els ciutadans no agrairien mai prou aquest acte de generositat d'Espanya, de la verdadera España.

\section{4: el risc d'«el olvido»}

«iCatalanes!: no olvidéis nunca que por la redención de esta querida tierra entregó España su mejor tesoro: ¡la sangre de su juventud!». ${ }^{\circ} \mathrm{El}$ crit d'alerta del Caudillo era un avís contra l'oblit galopant? O, senzillament, era una citació més per illustrar el record de la liberación? Dit en uns altres termes, calia entendre-ho com una amenaça? Qui s'atreviria a qüestionar - o a oblidar - una victòria que havia costat la sang de la joventut d'Espanya? Qui es podria atrevir a qüestionar el valor d'aquesta victòria?

L’any 1944 va ser dens a La Vanguardia Española. Luis de Galinsoga va farcir les pàgines de collaboradors i consignes, com si hi hagués pressa per commemorar la liberación en un moment de tombant de la guerra mundial i, per tant, de l'aparició de noves incerteses de futur. Semblava com si hi hagués pressa i la necessitat d'una major — si això era possiblecontundència. $O$ potser era que les denúncies per oblidar s'havien acumulat damunt les taules de les autoritats franquistes i els seus intellectuals; és a dir, que cada vegada es notava més que la gent no tenia cap ganes de commemorar segons què. Un personatge tan central en aquells moments com Juan Ramón Masoliver ho escrivia amb totes les lletres: «¿Qué ha pasado entretanto? El olvido. Olvidado como el asesinato de decenas de miles de personas decentes, como el incendio y pillaje de trescientas iglesias y capillas en la ciudad en el ominoso período anterior».51 Però, era cert que la ciutat havia oblidat? Des del mateix diari semblava que es desmentia un personatge d'aquesta categoria: «Ayer, quinto aniversario de aquella fecha, [...] Barcelona acudió a la cita evocadora que se le daba, con la mente cuajada de recuerdos y con el rostro placentero y amable del que ha sabido - y podido - superar un gran dolor»..5 Potser la contradicció, el punt de desacord, es trobava en qui havia oblidat i

50 Fragment de l'allocució radiofònica del general Franco des de Radio Nacional de España a Barcelona el febrer de 1939, reproduit a la portada de La Vanguardia Española, 26 gen. 1944.

51 Juan Ramón MASOLIVER, «Conjuro contra el olvido. Días como hoy, hace cinco años», La Vanguardia Española, 26 gen. 1944.

52 [Sense signar], «“...y se llenaron los aires de redobles castrenses”», 27 gen. 1944. 
què havia oblidat. Potser Masoliver no volia parlar tant de l'oblit com de l'abandonament de responsabilitats i compromisos. Alguns (qui?) havien oblidat el dolor i la tragèdia de la revolució i la cura dels vencedors l'any 1939; la cura profeixista de 1939. Què en quedava, l'any 1944, d'aquell tractament? No res. Per què? Perquè la gent havia oblidat la malaltia de 19361939 i el tractament indispensable i d'urgència que se li havia administrat.

Explicat d'una altra manera, hom podia dir: la gent no volia recordar el projecte falangista de 1939 i a l'any 1944 només aplaudia l'aliança entre l'Exèrcit, que desfilava, l'Església, que beneïa, i el Caudillo, que planava per damunt de tothom i es feia present en les persones de les autoritats oficials. Per exemple, en aquesta línia anava el recordatori de La Vanguardia Española, escrit molt probablement per Luis de Galinsoga: «Barcelona era el objetivo primario de la guerra desde hacía muchos meses, desde hacía muchos años, después de comenzada la guerra misma. Si no la hubieran señalado como tal las circunstancias históricas - viejas, modernas y contemporáneas - que hacen del Principado insigne pieza substancial en la ensambladura magnífica de la Unidad, los enemigos de España y de la propia Barcelona - queremos decir la sedición separatista y soviética-, lo habrían determinado como punto de mira para los catalejos avizores del Generalísimo y de su Estado Mayor».53 Aquí no hi havia retòrica falangista ni altres floritures per l'estil. Galinsoga només tenia una imatge al cap, l'aliança indestructible entre el Caudillo i l'Exèrcit, i la victòria de 1939 en termes de conquesta militar i espanyolització d'un territori que havia segrestat durant dècades per la «sedición separatista y soviética» —una fórmula, per cert, sorprenentment molt poc habitual en la literatura franquista de l'època. Catalunya havia estat «conquistada», «liberada», etc., i «recuperada para España», però no era gens freqüent la menció a l'aspecte contrarevolucionari de la liberación. Caldria estudiar per què l'aspecte «soviético» de la «sedición» apareix com un assumpte de segona categoria, com si la liquidació de la proposta social de la República i de les forces obreristes fos un element secundari en el gran projecte franquista amb relació a Catalunya.

Més enllà de la sinceritat de Juan Ramón Masoliver en reconèixer que hi havia coses que no anaven bé, Luis de Galinsoga havia preparat un pa-

53 Totes les citacions d'«Un objetivo espiritual», La Vanguardia Española, 26 gen. 1944. 
rell d'edicions, pels dies 26 i 27 de gener, força contundents, plenes de collaboracions de gent de confiança i d'amics, i que no deixaven respirar el lector. Per al dia 26, tenia un poema «antiseparatista» de Manuel Machado, que començava prou bé: «Y querían separarte de España — pedazo de España, el mejor-, porque tú eras rica y bella y podías bastarte a ti misma, ciudad privilegiada». El «Boceto de poema» continuava en aquesta línia — «Y querían hacerte enemiga», «Y querían desgarrarte», «Y pretendían arrancarla...»-, fins que Barcelona, i Catalunya, es van salvar:

Y te salvaste tú misma, te salvaste de esa cosa fea que es la ingratitud; de esa cosa odiosa que es la deslealtad; de esa monstruosidad que es el parricidio: el atentado a la integridad, [a la sagrada unidad de la Patria...

Te salvaste abriendo los brazos a tus libertadores, que acaudillaba

[Franco.

$\mathrm{Al}$ costat de l'inqualificable text del germà dolent - literàriament dolent- d'Antonio Machado, Eugenio Montes oferia una reflexió d'allò més interessant i oportuna al voltant d'una pregunta que demanava una resposta no gens fàcil: «¿Cómo este pueblo tan cuerdo, tan razonable, tan normal ha podido caer en tal insania?».54 Què havia portat Catalunya, «la comarca española más rica de burguesía», a l'abisme? Calia anar a trobar la resposta en «las doctrinas predicadas en Cataluña durante más de cincuenta años». Aquestes doctrines «partían del supuesto de que el resto de España era medular, temperamental y absurdo, mientras que allí se había refugiado el buen sentido. Partían de una posibilidad de destino diferente». Però l'Espanya rural, sense indústria, va imposar el seu sentit de civilització i va guanyar. Amb la collaboració, però, de molts catalans:

Ya muchos catalanes, dando la vuelta por el Pirineo, se habían sumado, en vanguardia y en retaguardia, al esfuerzo de la zona nacional. Los jóvenes de las falanges y de los tercios - ¡Oh Montserrat! - no habían cedido en heroísmo a los de ninguna otra región. Y los maduros habían hecho algo magnífico 
también: improvisar industrias, formas de vida técnica en Castilla, Extremadura, Andalucía.

Luego, fue Cataluña entera la que se sumó al esfuerzo último y decisivo. Eso permitió acabar nuestra guerra a punto, antes de que comenzase la mundial. Y permitió ganar la paz, la prosperidad presente.

Loor a la Cataluña burguesa y artesana, sin la cual no podríamos ser nación de alto rango europeo. Loor a la españolidad de las comarcas agrícolas, sin cuyo ardor no seríamos patria. ${ }^{55}$

Juan Aparicio - i aquesta era una collaboració de primeríssima categoria, tenint en compte el càrrec que ocupava-, empeltat de l'estil de l'època, imaginava el retorn de Don Quijote a Barcelona «para devolver a los catalanes la independencia que perdieron tan pronto como hubo de retirarse a su villorrio y se aprovecharon de su hipocondría y desarme moral gabachos y traidores».56

El periodista J. Cuartero, amic de Galinsoga, insistia en el deure de fer memòria: «Bien está la política de clemencia, el perdón discernido con las cauciones convenientes para traer a la concordia y a la unidad los espíritus capaces de contrición y enmienda, pero nunca el olvido que borra la decisión y la experiencia y algún día pueda ser descuido y lenidad ante los reincidentes. Hay que mantener la costumbre de las conmemoraciones. Hay que volver la vista al pasado, recorrer la llaga española de los ocho años infernales, alertar la memoria de los contemporáneos e instruir a las generaciones en causas, culpas, hechos oprobiosos y dolorosas enseñanzas de aquella revolución, inmunda y feroz, sin par ni semejanza en la Historia».57 Però Cuartero no ho acabava en aquest punt; darrere la consigna de recordar s'hi amagava la narració de què s'havia de recordar:

La República desmintió inmediatamente sus programas cautelosos y sus promesas de moderación. Se apoderaron de ella los demagogos, y desde el primer momento fue su signo el terror. Quema de templos y cosechas, devastación

55 Ibid.

56 Juan Aparicio, «Ensueño en Vallvidrera. El regreso de Don Quijote», La Vanguardia Española, 26 gen. 1944 .

57 Totes les citacions de J. Cuartero, «El alma nueva de España», La Vanguardia Española, 26 gen. 1944 . 
de los campos y de los cultivos, profusión de huelgas, indisciplina del trabajo, desorganización de las industrias, ruina de los negocios, vejación de patronos y empresas, despojo de propiedades, repercusión del desorden en toda la economía y en todas las funciones del crédito, atentados personales impunes, suelta de presidiarios y encarcelamiento de personas honradas, legislación perturbadora y agresiva en la Gaceta, persecución arbitraria y rencorosa de adversarios, interdicción casi permanente de garantías. Esto fue la República hasta febrero de 1936, en que ocupó el poder el Frente Popular, liga de todos los elementos disolventes que fomentó la anarquía y no tuvo reparo en dar algunos Ministerios a malhechores y licenciados de presidio. El asesinato alevoso de Calvo Sotelo por un grupo de la Policía colmó la indignación pública; estalló el Alzamiento nacional, y el Gobierno armó a las turbas, a cuantos criminales quisieron el fusil y la impunidad para el asesinato y el robo; decretó movilizaciones crueles y abusivas de forzados; apartó del trabajo a los obreros; paralizó todas las producciones; robó el oro y todos los valores negociables en oro del Banco de España y de la Banca privada; robó también oro, joyas y valores de los particulares en los domicilios y en los depósitos bancarios; multiplicó sin medida la inflación del papel moneda; sembró la miseria y el hambre; consintió, indiferente o complacido, la carnicería de las checas y los "paseos", muchos millares de asesinatos: hasta ochenta mil sólo en Madrid.

No hi ha memòria sense una història digna de ser recordada, i l'experiència de la República i la guerra complia tots els requisits perquè no fos oblidada. Per tant, el periodista feia allò que calia: explicar què havia estat la República, segons els paràmetres discursius i memorialístics del franquisme, i, immediatament, llançar la consigna: recordem això que acabo d'explicar, el relat únic possible - el franquista - dels fets. A una història oficial li corresponia una memòria oficial i l'obligació de la ciutadania de recordar.

Qui recordava, i amb un notable entusiasme, era Eugenio d'Ors. El pensador i acadèmic era, probablement, el gran trumfo de Luis de Galinsoga per al seu equip d'intellectuals. Cap dels que l'acompanyaven a les pàgines del diari li podia fer la competència, ni tenia un currículum tan envejable com el seu. D'Ors ho tenia tot: l'intellectual català traslladat, de feia anys, a Madrid; el renegat històric, ara traïdor definitiu, que es feia present en els pitjors moments de la història catalana, de la mà del franquista més 
descarat entre els molt descarats que circulaven per Barcelona. En les llistes de collaboracionistes que s'elaboraven en la clandestinitat i l'exili, D’Ors hi tenia reservat un lloc d'honor, al costat dels homes de Destino. Aquell any 1944, D’Ors va explicar als seus lectors les gestions fetes a Ginebra per recuperar les obres d'art que el Govern de la República havia evacuat de Madrid durant la guerra. Les peces artístiques, provinents de diversos museus, van anar a raure a la seu de la Societat de Nacions, tot esperant les negociacions que es posessin en marxa un cop acabada la guerra i reconegut definitivament el govern franquista. D'Ors, explicava, va sortir ràpidament de Vitòria, amb l'encàrrec oficial de recuperar «un incomparable patrimonio de España y del Espíritu». Les negociacions amb el secretari general de la Societat de Nacions no van donar resultats, i va ser necessari esperar que la ciutat de Ginebra organitzés una gran exposició amb les peces evacuades per poder-les recuperar. ${ }^{58}$ D'Ors no podia oferir gran cosa més als lectors catalans. A pesar del nom, tenia més passat que present i futur en el camp intellectual del franquisme català; era una signatura de prestigi, però no de pes. Massa anys fora de l'ambient català, massa llegenda negra perquè pogués remuntar. Era un gran fitxatge de Galinsoga, però desproporcionat en relació amb els resultats que podia donar. ${ }^{59}$

Una de les collaboracions més notables d'aquell any va ser la del canonge José Montagut Roca, un dels millors propagandistes del franquisme a la postguerra. El canonge s'havia fet famós - merescudament famósl'any 1939, quan va publicar un programa d'actuació envers la llengua catalana, que era una de les propostes més radicals de liquidació del català com a llengua culta, d'ensenyament, d'ús públic, etc. ${ }^{60} \mathrm{Cinc}$ anys més tard, apareixia a La Vanguardia Española per parlar de la «reconquista espiritual del pueblo», missió central de «La Iglesia en la paz de Franco. Retorno a la tradición». ${ }^{61}$ Home d'afirmacions contundents, el canonge Mon-

58 Vegeu Eugenio D’Ors, «Recuerdos en esta jornada», La Vanguardia Española, 26 gen. 1944.

59 De tota manera, però, era una figura de primer ordre en la cort intellectual franquista catalana, quan apareixia per Barcelona. O, almenys, aquest és el record d'Ignasi Agustí a Ganas de hablar (Barcelona: Planeta, 1974).

6o José Montagut Roca, «El Estado Nacional frente al problema de la pluralidad de lenguas», Solidaridad Nacional, 6 nov. 1939.

61 Totes les citacions de José Montagut RocA, «La Iglesia en la paz de Franco. Retorno a la tradición", La Vanguardia Española, 26 gen. 1944. 
tagut era perfectament conscient que «el rescate de las almas» era «más laborioso» «que la liberación de las ciudades»: «Domeñada la revolución, su espíritu pervive, se resiste a desaparecer, y a través de mil filtros se difunde en un ambiente acogedor y hasta burla a veces las normas estatales mejor inspiradas, obstruyendo su eficacia». Certament, en aquells anys s'havia progressat força, gràcies, sobretot, a les virtuts que ornamentaven la persona del Caudillo: «El espíritu del creyente, la probidad del ciudadano, y el valor del cruzado, forman una triple aureola sobre la frente del Jefe del Estado». A continuació, citava algunes de les realitzacions: uns sindicats verticals, que «son la reproducción de los Gremios, adaptados a las exigencias del industrialismo moderno»; «la redención de los presos por el trabajo», producte de «la generosa comprensión del Caudillo, expresión de sus delicados sentimientos»; «la munificiencia en la erección de nuevos templos o en la reconstrucción de los derruídos por el huracán revolucionario»; tots ells eren aspectes cabdals d'una recuperació d'Espanya com mai no s'havia vist. A tot plegat, calia incorporar-hi dos elements transcendentals: el control del sistema educatiu per l'Església — «se ha investido a los obispos y párrocos de los derechos inherentes a su sobrenatural ministerio para controlar la realidad y pureza de la enseñanza católica»—, i la plena catolització del falangisme unificat, fugint de l'anticlericalisme més radical dels primers moments. Però, i aquesta era la pregunta clau, tot plegat era suficient? Sorprenentment, el canonge admetia la derrota, encara que només fos temporal: «esa evolución hacia una meta superior, lograda en tiempos más felices, no está exenta de defectos, no imputables a las directrices del Estado, ni a la resuelta voluntad del Caudillo, sino - aparte factores extrínsecos - al noviciado de instrumentos improvisados por la necesidad, a la exigua densidad espiritual de algunos colaboradores, y principalmente al desequilibrio existente entre un Estado perfectamente orientado hacia un objetivo de superación, y una sociedad que, pulverizada y gangrenada por la revolución, no acierta a ponerse a tono con las normas que el Poder público legisla, y unas veces remisa, y otras rebelde, invalida su existencia o paraliza su eficacia».

Era la mateixa lamentació de Masoliver i altres collegues del diari: alguna cosa no marxava prou bé en els rengles ciutadans, aquell any 1944. Uns no volien recordar; altres havien oblidat; uns altres eren, encara, «españoles durmientes o extraviados», que no s'havien situat prou bé en 
la nova realitat de la Nueva España. Tot plegat quedava molt lluny de la imatge oficial d'entusiasme general i mobilitzacions collectives, que es transmetia contínuament.

Però la commemoració d'aquell cinquè aniversari no s'acabava aquí. Impressiona veure l'esforç que va invertir el diari —i Luis de Galinsoga al capdavant - perquè aquell any 1944 fos recordat amb tots els honors. Aquell va ser l'any més lluït, pel que feia a collaboracions, de tota la primera dècada franquista. Potser el tomb de la guerra obligava a marcar un perfil més clar; o potser es tractava d'advertir la ciutadania - bona part de la qual, segons les informacions falangistes, era partidària de la victòria aliada en la segona guerra mundial- que res no es mouria, passés el que passés. ${ }^{62} \mathrm{El}$ articles de Joaquin Arrarás («Aquella batalla del Ebro... Cómo se disolvió la resistencia de Barcelona»), José M. Pemán («La entrada de Don Quijote en Barcelona»), Francisco de Cossío («La vuelta a la Historia») o Felipe Sassone («En el aniversario de la liberación. ¡La fecha nada más!»), tots publicats el 26 de gener de 1944, eren una música de fons contínua, que feia evidents dues coses: en primer lloc, que l'opinió sobre la liberación de Barcelona era un assumpte nacional, en el qual la intervenció dels nous intellectuals del règim era imprescindible; en segon lloc, que el record de la guerra i l'instant de la liberación eren una creu que la societat catalana havia d'assumir al més aviat millor i, en els nous rituals de la dictadura, recuperar cada any, com a acte de penitència i acatament als libertadores.

En aquest panorama de conjunt, que un economista català prestigiós com Josep M. Tallada hagués acceptat de fer el paper de collaborador indígena de l'operació galinsoganiana - juntament amb el desaparegut Ferran Valls Taberner i Josep M. Junoy, principalment-, ens hauria de fer pensar, amb profunditat, sobre aquest fenomen que, en els anys següents, es va anomenar "collaboracionisme català", fent un parallelisme evident amb el cas francès. ${ }^{63}$ Tallada havia fet acte de presència al diari en

62 Carles SAntacana I TorRes, «Actituds catalanes davant de la Segona Guerra Mundial», dins Borja de RiQuer, dir., Història, política, societat i cultura dels Països Catalans, vol. 10: La llarga post guerra, 1939-1960 (Barcelona: Enciclopèdia Catalana, 1998), 228-229.

63 La campanya contra el «collaboracionisme» català va tenir el seu gran moment en els mesos posteriors a la fi de la guerra a Europa, i la van impulsar, sobretot, des de la clandestinitat els primers nuclis catalanistes reorganitzats després de la Guerra Civil: TAURUS, «El collaboracionisme i la nos- 
el curt temps del tàndem directiu Josep Pla/Manuel Aznar i va continuar, amb notable intensitat, amb Luis de Galinsoga. Si la gent de Destino ja era conceptuada com a traïdora, Josep M. Tallada era a l'extrem de l'espectre. I, per reblar-ho, era un dels pocs catalans d'origen i formació regionalista/catalanista en el món cambonià d'abans de la guerra que es manifestava públicament i sense embuts en la principal plataforma franquista del país.

Què explicava, Josep M. Tallada, aquell any? Després d'agrair a l'exèrcit espanyol l'«instante glorioso de la liberación material» ${ }^{64}$ de Barcelona; després d'afirmar, amb tota contundència, la «perfecta unanimidad» del poble davant la «liberación», Tallada anava a buscar les arrels de la tragèdia, sobretot les arrels ideològiques. Els mals venien, abans de res, de Pi i Margall i, darrere d'ell, de Proudhon. Com que a Catalunya es coneixia força bé la llengua francesa, després van arribar Fourier i Cabet, per culminar el programa amb Georges Sorel, «el verdadero director espiritual de nuestros obreros». Amb la Primera Internacional, van comparèixer Paul Lafargue i Giuseppe Fanelli, «representante de las ideas de Bakunin en la Internacional obrera», que va dedicar una atenció especial al territori català. Davant d'aquesta dinàmica d'adoctrinament dels treballadors -que hauria començat amb el republicanisme i el federalisme, i hauria acabat amb l'anarquisme-, què havien fet «los elementos conservadores»?, preguntava Josep M. Tallada:

No teorías espiritualistas, no orientaciones idealistas. Nada de Nietzsche, por ejemplo, tan en boga a fines del pasado siglo, de los católicos sociales franceses. Cuando se formaban los hombres que actuaron como orientadores de la burguesía a finales del siglo pasado y comienzos de éste, estaba de moda el francés Taine, y en los Centros escolares de aquella época las ideas de tal autor, que todos podían leer en francés, tuvieron gran influencia. El clima, la raza, la lengua, el medio ambiente, influyen, según Taine, en la formación e historia

tra cultura», Orientacions [Barcelona] 3 (març 1945); SAGITARI, «El problema del collaboracionisme», Orientacions 4 (abr. 1945); «Collaboracionisme», Per Catalunya [s./n.] (ag. 1945); «Collaboracionistes i traïdors fins a la mort», Per Catalunya 11 (oct. 1945); «Collaboracionisme», Per Catalunya 12 (nov. 1945); «Supervivència dels botiflers», Germanor 508-509 (jul. 1946); etc.

64 Totes les citacions de José M. TAlLadA, «Liberación espiritual», La Vanguardia Española (26 gen. 1944). 
de los pueblos, concepción materialista propia tan sólo para reducir las áreas de la influencia ideológica y que desde el otro lado de la barricada coincidía en facilidades con las orientaciones de Pi y Margall.

El text tenia poc a veure amb la commemoració estricta, però era coherent amb moltes intervencions anteriors de Tallada, començant ja amb els articles de 1939. L'economista, com el seu collega periodístic Santiago Nadal, estava obsessionat amb la qüestió d'una «burgesia traïdora», «sense ànima», que, partint d'elements ideològics equivocats havia acabat essent còmplice de la revolució del segle Xx. ${ }^{65}$

Si la contribució de Josep M. Tallada — a més a més de ser interessantera força singular, la resta de collaboracions ja tornaven a la línia habitual: L. Renart i G. Serra recordaven la «gloria» i l'«honor» del Tercio de Requetés de Nuestra Señora de Montserrat, ${ }^{66}$ Luis Fontes de Albornoz feia una mica més de memòria de la cinquena columna falangista. ${ }^{67}$ Eduardo Marquina, convertit ja en el poeta oficial del franquisme català, aportava uns versos horribles publicats el 27 de gener de 1944 sota el títol «A Cataluña recobrada», que acompanyava una fotografia de la Mare de Déu de Montserrat:

¡Tregua a los años de esterilidad en el establo hermético, sin delirios de pañales!

¡Tres veces se perdió la Navidad

En la boca del lobo de tus laicos portales!

(II:v. 9-12)

Sense cap mena de dubte aquell any 1944 va representar l'esforç titànic més gran que va fer el diari en tota la dècada dels quaranta per commemorar com es mereixia el cinquè aniversari de la liberación de Bar-

65 Francesc Vilanova, Una burgesia sense ànima. El franquisme i la traïció catalana (Barcelona: Empúries, 2010).

66 L. RenART \& G. SERRA, «Gloria y honor al Tercio de Requetés de Nuestra Señora de Montserrat», La Vanguardia Española, 26 gen. 1944. Aprofitant el lliurament de la Cruz Laureada, L. Renart i G. Serra van publicar el mateix article a Diario de Barcelona, 26 gen. 1944.

67 Luis Fontes de Albornoz, «26 de enero en el Palacio de San Jorge», La Vanguardia Española, 27 gen. 1944. En canvi, a Solidaridad Nacional la seva contribució era completament diferent: «Sabadell, esquema de la voluntad de un pueblo», 27 gen. 1944. 
celona. Va ser el punt més àlgid, el moment més intens per visualitzar la nova classe intellectual del règim, la nova intelligentsia que, de Madrid a Barcelona, feia acte de presència — finalment! — en territori català, amb una clara vocació de quedar-s'hi: Manuel Machado, Eugenio Montes, Eugenio d'Ors, Juan Aparicio, Joaquín Arrarás, José M. Pemán, Francisco de Cossío, Eduardo Marquina... En altres grans ocasions — 1 d'abril, 18 de juliol, etc.-, Galinsoga convocava més amics: Melchor Fernández Almagro, José Francés, José Ibáñez Martín, Eduardo Aunós, entre altres, sense oblidar els habituals. El desplegament era abassegador i ideològicament despietat. Però aquesta era la missió de Luis Martínez de Galinsoga a Catalunya: desasnar els catalans, sol o amb amics incondicionals, provinents de la Nueva España. 